\title{
ELUTION OF METRONIDAZOLE AND GENTAMICIN FROM POLYMETHYLMETHACRYLATE BEADS
}

\author{
by \\ José Rafaelix Ramos
}

Thesis submitted to the faculty of the Virginia Polytechnic Institute and State University in partial fulfillment of the requirements for the degree of

\author{
MASTER OF SCIENCE \\ in \\ Veterinary Medical Sciences
}

Approved:

Rick D. Howard, Chairman

R. S. Pleasant

Dennis J. Blodgett

May 2, 2002

Blacksburg, Virginia

Key Words: Metronidazole, Gentamicin, Polymethylmethacrylate, Beads, Elution

Copyright 2003. José Rafaelix Ramos 


\title{
ELUTION OF METRONIDAZOLE AND GENTAMICIN FROM POLYMETHYLMETHACRYLATE BEADS
}

\author{
By \\ José Rafaelix Ramos \\ Rick D. Howard, Committee Chairman \\ Department of Large Animal Clinical Sciences
}

(ABSTRACT)

Ten polymethylmethacrylate (PMMA) beads containing metronidazole (3 concentrations); gentamicin sulfate; or metronidazole and gentamicin sulfate were immersed in $5 \mathrm{ml}$ of phosphate buffered saline in triplicate. Eluent was replaced at specified time intervals for 1 day (1, 3, 6, 12 and 24 hours), daily, or weekly for 21 days. Antibiotic concentrations were measured by High Performance Liquid Chromatography. Changes in antibiotic bioactivity attributable to polymerization or co-polymerization of the antibiotics with PMMA, ethylene oxide sterilization, and storage of antibioticimpregnated PMMA (AIPMMA) beads containing metronidazole were evaluated.

Antibiotic elution patterns were similar for all groups. Day-1 elution for groups containing either metronidazole (3 concentrations) or gentamicin represented a mean $63 \%$ to $66 \%$ and $79 \%$ respectively of the 21 -day total elution. Approximately $50 \%$ of the day-1 elution occurred during the first hour. The elution of metronidazole was dosedependent. There was no significant difference in the total amount of antibiotic eluted from groups that had the saline changed daily versus weekly. The elution of metronidazole (day 3-21) and gentamicin (all days) was significantly greater when metronidazole and gentamicin were combined $(\mathrm{p}<0.05)$. Polymerization of PMMA was delayed in groups containing metronidazole. Neither polymerization nor copolymerization of metronidazole and gentamicin with PMMA, gas-sterilization, or 2month storage of beads containing metronidazole significantly affected antimicrobial bioactivity.

Metronidazole elutes from PMMA. The frequency at which the saline was changed did not affect the rate of antibiotic elution. Co-polymerization of metronidazole 
and gentamicin sulfate in PMMA resulted in increased rates of elution. Intra-operative preparation of metronidazole-impregnated PMMA beads is not practical. However, prefabrication of metronidazole or metronidazole-gentamicin beads, gas-sterilization and storage for up to 2 months should not affect the efficacy of either antibiotic. The local delivery of biologically active metronidazole and gentamicin by elution from PMMA is feasible. 
To Flavia, my wife, for her never-ending patience, love and support; to Flavia Alexandra and Isabella Andrea for forgiving me for not spending enough time with them and always waiting for me with open arms; to my parents (Rafo and Awilda) and parents in law (José Alberto and Gloria) for their continuous love and support;

\section{$A N D$}

to Puerto Rico, because it watched me grow, and surrounded me with the family and friends who molded my personality, built up my character and taught me the values that have allowed me to succeed in life. Puerto Rico, I thank you for being a continuous source of inspiration to me and the rest of your children. 


\section{ACKNOWLEDGEMENTS}

I would like to thank Dr. Rick Howard, my residency program and graduate studies advisor for his guidance, patience and encouragement throughout my graduate program, and for helping me become a surgeon, a better man, a better husband and a better father. He truly was an excellent advisor in and out of the academic environment.

I sincerely thank the other members of my graduate committee, Drs. R. Scott Pleasant, and Dennis J. Blodgett for their patience, willingness to help me understand certain concepts concerning veterinary research, and for their contribution to this work. I would also like to thank Dr. H. David Moll, who was my resident and graduate studies advisor during my first year at Virginia Tech and who helped me prepare my thesis proposal. My gratitude is also extended to Dr. M. Norris Adams, my dear friend and surgery instructor, who contributed to this work with his clinical experiences using antibiotic-impregnated PMMA beads.

Special thanks are extended to Dr. Geraldine Magnin, who made this study possible by determining antibiotic concentrations using high performance liquid chromatography. Additional thanks are due to Drs. Thomas J. Inzana and Nammalwar Siranganathan whose guidance and expertise in bacteriology allowed me to perform an important part of this project, the testing of antimicrobial bioactivity. I would also like to thank Mrs. Dawn Jones and Susan King for their guidance, help and expertise in bacteriology laboratory techniques. I also thank Vivian Takafuji and Eileen Strahl for their technical assistance and expertise in bench top research techniques. I thank Dan Ward for his assistance with the statistical analysis of data resulting from this study. The help from my wife Flavia, who labeled all the test tubes for me, is also greatly appreciated.

Finally, I acknowledge Dr. Tim Long and his student Kayleen Gloor, who used gel permeation chromatography (GPC) to determine whether or not the addition of metronidazole or gentamicin altered the molecular weight of PMMA, therefore affecting its biochemical composition. 


\section{TABLE OF CONTENTS}

ABSTRACT

ACKNOWLEDGEMENTS iv

LIST OF FIGURES vii

INTRODUCTION 1

REVIEW OF LITERATURE 4

INDICATIONS FOR LOCAL DELIVERY OF ANTIBIOTICS 4

Infectious Synovitis $\quad 4$

Infected Fractures and Fracture Fixation Implants 5

Infectious Physitis/Osteomyelitis 5

Prognosis 6

Methods Of LOCAL DELIVERY OF ANTIBIOTICS 6

$\begin{array}{ll}\text { Intra-articular Injection } & 7\end{array}$

Regional Limb Perfusion $\quad 7$

Biodegradable Drug Delivery Systems (BDDS) 8

Non-Biodegradable Drug Delivery System (AIPMMA) 9

History 9

General Concepts 10

Biomechanical Strength 12

Clinical Use in Large Animals $\quad 12$

Antimicrobial Selection 13

Implant Preparation 15

$\begin{array}{ll}\text { Antimicrobial Elution } & 15\end{array}$

Mechanism of Drug Release 18

$\begin{array}{ll}\text { Advantages } & 19\end{array}$

Disadvantages and Complications 19

$\begin{array}{ll}\text { ANTIMICROBIAL CHARACTERISTICS } & 21\end{array}$

$\begin{array}{ll}\text { Gentamicin Sulfate } & 21\end{array}$ 
Metronidazole 23

MATERIALS AND METHODS 25

$\begin{array}{ll}\text { ELUTION STUDIES } & 25\end{array}$

Fabrication of AIPMMA Beads 25

Experimental Procedures $\quad 25$

Metronidazole Analysis $\quad 27$

Gentamicin Analysis $\quad 27$

$\begin{array}{ll}\text { ASSESSMENT OF ANTIMICROBIAL BIOACTIVITY } & 28\end{array}$

Preparation of Test Solutions 28

Culture Methods 28

Assessment of Bacterial Growth 29

Statistical Analyses $\quad 29$

$\begin{array}{ll}\text { RESULTS } & 30\end{array}$

$\begin{array}{ll}\text { ANTIMICROBIAL ELUTION } & 30\end{array}$

Elution of Metronidazole $\quad 30$

Elution of Gentamicin 31

Co-elution of Metronidazole and Gentamicin 31

$\begin{array}{ll}\text { ANTIMICROBIAL BIOACTIVITY } & 32\end{array}$

Metronidazole Bioactivity $\quad 32$

Gentamicin Bioactivity $\quad 32$

DISCUSSION 33

CONCLUSION 43

LITERATURE CITED 44

$\begin{array}{ll}\text { VITA } & 60\end{array}$ 


\section{LIST OF FIGURES}

Figure 1. Metronidazole elution from PMMA beads 54

Figure 2. Comparison between daily and 24 hour/weekly collection of samples 55

Figure 3. Gentamicin elution from GENT and MET/GENT beads 56

Figure 4. Metronidazole elution from MET 20:1 and MET/GENT beads 57

Figure 5. Bioactivity of eluted metronidazole 58

Figure 6 Bioactivity of eluted gentamicin $\quad 59$ 


\section{INTRODUCTION}

Orthopedic infections are common in horses (Schneider and Moore 1992) and often complicated by factors that render them refractory to conventional systemic therapeutic strategies. These infections often result from traumatic injuries, as is the case of open fractures and wounds that penetrate joints or tendon sheaths, and may be associated with extensive soft tissue damage. The development of orthopedic infections (infectious arthritis/tenosynovitis, infected fractures, and osteomyelitis) can result in career or life ending consequences for horses. The traumatic nature of these injuries and associated soft tissue damage may promote the development of infection through direct bacterial contamination and impairment of local immune responses (Holcombe 1997). The resulting impairment of local immunity can make treatment of these infections challenging. Furthermore, bacterial infections can develop around stainless steel orthopedic implants (bone plates and screws) used for repair of fractures, particularly those that are open. Bacteria infecting these implants may produce a thick, fibrous biofilm (glycocalyx) that facilitates bacterial adherence to the implants, entrapment of nutrients and acts as a physical barrier that hinders antimicrobial and cellular access to bacteria (Holcombe 1997; Kanellakapolou 2000). Consequently, systemic administration of antibiotics may be ineffective in the treatment and prevention of bacterial infections under these circumstances. High concentrations of locally delivered antibiotics may help overcome these defensive mechanisms (Holcombe 1997; Schneider 1999).

Antibiotic-impregnated polymethylmethacrylate (AIPMMA) has been suggested to be one of the best methods of delivering antibiotics locally to the site of infection (Schneider 1999). The use of AIPMMA has been advocated for the treatment of orthopedic infections, due to its potential to deliver and sustain high concentrations of antibiotics locally for prolonged periods of time. Increased concentrations of antibiotics may improve the spectrum of susceptible organisms for some antimicrobial agents (Henry 1991; Henry 1993). Antimicrobial tissue concentrations in wounds, treated locally with AIPMMA beads, have been shown to be as much as 20 times the therapeutic levels attained in serum following systemic administration (Henry 1991; Henry1993). Antibiotic-impregnated polymethylmethacrylate has been used successfully as an 
adjunctive therapy in large animals, for the treatment of orthopedic infections that were refractory to other treatment modalities, such as long-term systemic antibiotic administration, joint or tendon sheath lavage and drainage, and surgical debridement (Butson 1996; Trostle 1996; Holcombe 1997).

The family Enterobacteriaceae has been reported to be the group of organisms most commonly isolated from equine orthopedic infections (Hirsh 1987; Snyder 1987), particularly those caused by penetrating wounds (Schneider and Moore 1992). Accordingly, gentamicin sulfate-impregnated polymethylmethacrylate has been used for the treatment of horses with infected fractures with and without implants, infectious arthritis and infectious tenosynovitis, and osteomyelitis (Butson 1996; Holcombe 1997). Like Enterobacteriaceae, anaerobic bacteria are part of the normal equine gastrointestinal flora and commonly encountered in the horses' environment. Retrospective studies indicate that in cases of equine orthopedic infections due to penetrating wounds, lacerations and open fractures, obligate anaerobes are the second most common cause of infection following Enterobacteriaceae (Hirsh 1987; Schneider and Moore 1992). Results of one study showed a $26.3 \%$ incidence of anaerobic pathogens in cases of equine infectious synovitis, resulting from penetrating wounds (Schneider and Moore 1992). Furthermore, the authors of that study suggested that since not all samples collected were submitted for anaerobic culture, the actual incidence of anaerobic bacteria in equine infectious synovitis might be higher. Metronidazole is an antimicrobial commonly used in veterinary medicine for the treatment of anaerobic infections (Sweeney 1991; Moore 1993b). In a retrospective study of 823 clinical specimens from domestic animals, that cultured positive for anaerobic bacteria, all anaerobes were susceptible to metronidazole (Hirsh 1985).

The overall objective of this study was to determine the elution properties of a combination of metronidazole and gentamicin sulfate from polymethylmethacrylate (PMMA) beads. Although metronidazole-impregnated PMMA has been used previously for the treatment of anaerobic infections (Trostle 1996), controlled studies evaluating the elution of metronidazole from PMMA have not been reported. The objectives of this study were to characterize the elution of metronidazole, gentamicin and their co-elution from PMMA beads; to determine the effect of frequency of saline changes on antibiotic 
elution from PMMA; to assess the bioactivity of the eluted antimicrobials following polymerization of individual or combined antimicrobials with PMMA, following sterilization of AIPMMA beads with ethylene oxide gas, and storage of PMMA beads containing metronidazole. 


\section{REVIEW OF LITERATURE}

\section{INDICATIONS For LOCAL DELIVERY OF ANTIBIOTICS}

As previously stated, traumatic orthopedic injuries are common in horses (Moore 1992; Schneider and Moore 1992; Butson 1996; Holcombe 1997). Due to the relative lack of soft tissue in the distal limb, these injuries can easily enter a joint capsule, tendon sheath or result in an open fracture. Infection develops in these cases through direct bacterial contamination, but is facilitated by the disruption of blood supply and lymphatic drainage, which results in impairment of local immunity (Holcombe 1997). Once infection is established, resulting disease processes include infectious synovitis, osteomyelitis or infected fractures.

\section{Infectious Synovitis}

In cases of infectious synovitis (infectious arthritis or infectious tenosynovitis), inflammatory cells (mainly neutrophills) invade the synovial cavity in response to bacterial colonization. If infectious arthritis goes untreated, proteolytic enzymes, released by bacteria and inflammatory cells, eventually cause the loss of articular cartilage extracellular matrix (proteoglycan, followed by a loss of collagen) and subsequent cartilage destruction (McIlwraith 1983). Irreversible cartilagenous damage will lead to the development of osteoarthritis. Furthermore, chronic synovitis may result in necrosis of the synovial membrane and extensive fibrinopurulent exudation. Inflammatory exudates, particularly infectious exudates, form fibrin. Fibrin formation in a joint interferes with the synovial membrane's role of nourishing articular cartilage, leading to further cartilage destruction and development of osteoarthritis (McIlwraith 1983). Depending on its severity, osteoarthritis often ends the horse's athletic career. In addition, infection that destroys articular cartilage can propagate into deeper tissues resulting in osteomyelitis. In the case of infectious tenosynovitis, fibrin deposition leads to the formation of fibrinous and subsequently, fibrous adhesions. Even if the infection subsides, the pain resulting from these adhesions could also end the horse's athletic career. 


\section{Infected Fractures and Fracture Fixation Implants}

Osteomyelitis or infection of a surgically repaired fracture or arthrodesis can occur subsequent to open wounds, bacterial contamination during the repair or incisional complications after the surgery. Infection can be a devastating complication of a repaired fracture or arthrodesis (Schneider 1999). Infection delays the healing process, promotes loosening of the implant and subsequent fracture instability, decreases weight bearing on the limb (increasing the risk of developing laminitis in the opposite limb), increases hospitalization time and cost of treatment (Schneider and Meckleburg 1992; Schneider 1999). The combination of infection and fracture instability is a reliable recipe for treatment failure (Schneider 1999).

\section{Infectious Physitis/Osteomyelitis}

Osteomyelitis is a bone infection involving the cortical bone and the marrow cavity of membranous or long bones. Osteomyelitis can occur as a result of trauma, as previously discussed for infectious synovitis and infected fractures, or subsequent to hematogenous spread of infection. Hematogenous spread of infection occurs uncommonly in adult horses (Schneider and Moore 1992), but is more common in foals less than 6 months of age (Martens 1986; Schneider and Moore 1992; Sayegh 2001). Septicemia, omphalophlebitis, gastroenteritis and pneumonia are common sources of bacteria that will travel through the bloodstream resulting in osteomyelitis or infectious synovitis (Sayegh 2001). The metaphyseal vascular anatomy of long bones in young growing horses predisposes them to this problem. Vascular sludging and blood stasis in the venous sinusoids of the transphyseal vasculature results in low oxygen tension, which establishes a suitable environment for bacterial growth. When bacteria gain access to the transphyseal vasculature, as in cases of septic physitis, they can create focal abscesses in the metaphysis or epiphysis (osteomyelitis), or they can propagate through the highly vascular synovium into an adjacent joint (infectious arthritis) (Martens 1986; Sayegh 2001). 


\section{Prognosis}

In a retrospective study of 192 horses with infectious arthritis/tenosynovitis, the prognosis for short-term survival (until discharge) was $85 \%$ for adult horses and $45 \%$ for foals. Horses with infectious tenosynovitis had a $100 \%$ short-term survival rate. Approximately $56.5 \%$ of racehorses returned to racing and $45 \%$ made at least 5 starts. The authors concluded that horses can return to athletic function, if infection is eliminated before irreversible cartilage damage occurs (Schneider and Moore 1992). When osteomyelitis accompanies infectious arthritis, the prognosis is dramatically decreased (Cook 1998). The prognosis for foals with infectious physitis/arthritis and osteomyelitis was reported to be guarded to poor (Martens 1986). Furthermore, in chronic or severe cases, the persistence of joint infection can be devastating for the athletic horse and is still a common cause of long-term loss of function or death (Butson 1996). In another study of 58 horses with open joint injuries, 16 of 58 horses were euthanized on admission because of the severity of the injury, poor prognosis for soundness, or for economic reasons. Of the 41 horses in which treatment was pursued, 20 were euthanized at a later date. The overall survival rate after development of infection in that study was 39\% (Gibson 1989).

The prognosis for horses with an infected fracture is also unfavorable. Only $52.9 \%$ of horses with an infected fracture or arthrodesis survived to discharge from the hospital (Schneider 1999). Potentially, improvement in the treatment of these cases could be made with the use of AIPMMA implants at the fracture site. In one study, 12 of 19 horses with infected fractures or joints survived long term after the infection was treated with AIPMMA (Holcombe 1997). Nevertheless, delayed healing, arthritis and other complications of orthopedic infections, still occur frequently resulting in loss of use of the horse (Schneider 1999).

\section{Methods Of Local Delivery OF ANTIBIOTICS}

Reduction in blood supply (as a result of trauma), accumulation of fibrin and inflammatory exudate (in infected joints and tendonsheaths) and necrotic bone (in cases of infectious physitis and osteomyelitis) are factors that may impede systemically administered antibiotics from reaching the site of infection in therapeutic concentrations. 
In some cases, particularly those of chronic duration, standard treatments such as lavage, drainage, debridement and curettage have also proved ineffective in resolving the infection. High concentrations of antibiotics, delivered directly to the infection site, may improve the treatment of these cases (Butson 1996; Holcombe 1997; Schneider 1999). A variety of techniques have been used to achieve high antibiotic concentrations at the infection site.

\section{Intra-articular Injection}

One way to achieve high concentrations of antibiotics in joint fluid is to combine systemic antibiotic therapy with intra-articular injection of antibiotics. Simultaneous administration of intravenous $(2.2 \mathrm{mg} / \mathrm{kg})$ and intra-articular $(150 \mathrm{mg})$ gentamicin resulted in a mean peak synovial fluid concentration $(5,720 ? \mathrm{~g} / \mathrm{ml})$ that was higher than the concentration achieved after intra-articular injection alone $(1,828 ? \mathrm{~g} / \mathrm{ml})$ and that achieved after intravenous injection alone (2.53 ?g/ml) (Lloyd 1988). That study also showed that the half-life of gentamicin in synovial fluid after intra-articular (IA) administration (259 minutes) was 2.8 times that of plasma after intravenous

administration (92 minutes). Gentamicin concentrations in synovial fluid remained above the minimum inhibitory concentration of gentamicin for common equine bacterial pathogens for 24 hours after IA administration. Intra-articular administration of gentamicin, amikacin and cefazolin was part of the treatment regimen used to eradicate the infection from joints and tendon sheaths of 25 of 26 horses in another study (Schneider and Mecklenburg 1992).

\section{Regional Limb Perfusion}

Regional limb perfusion is commonly used in cases of infection involving the distal limb of horses (infectious arthritis, infectious tenosynovitis, infectious physitis, or osteomyelitis). Regional limb perfusion is a method for delivery of antibiotics into the venous system either by intraosseous or intravenous infusion. Intravenous infusion of $125 \mathrm{mg}$ of amikacin in the distal limb resulted in antibiotic concentrations $25-50$ times the minimum inhibitory concentration (MIC) of this antibiotic against common equine bacterial pathogens (Santschi 1998). At these high concentrations, antibiotics may reach 
infected, ischemic areas that are not effectively perfused during infection. In a study of 29 horses with distal limb infection, intravenous antibiotic perfusion of the distal limb resulted in an $86 \%$ survival rate, with many of these horses returning to soundness (Santschi, 1998). It is important to remember that regional limb perfusion is most practically used in conjunction with surgical debridement. In another study, regional limb perfusion was used successfully to treat three horses with osteomyelitis associated with infected orthopedic implants (Whitehair, 1992).

\section{Biodegradable Drug Delivery Systems (BDDS)}

Many biodegradable materials have been used recently, or evaluated for use as drug delivery systems. These materials have the potential to replace their nonbiodegradable counterparts, because they do not require removal from the patients and they elute higher concentrations of antibiotics. A collagen-gentamicin sponge (biodegradable material) has been used successfully over the last decade for treatment of bone infections in humans (Kanellakopoulou 2000). Hydroxyapatite cement has also been used successfully in humans for the treatment of infected orthopedic implants (Eitenmuller 1985). Little research has been done regarding the use of these materials in veterinary medicine. The use of two biodegradable materials, poly $\{\mathrm{D}, \mathrm{L}\}$-lactide-coglycolide and poly\{D,L\}-lactide, was evaluated in vitro for their potential in the treatment of infectious arthritis in horses (Cook 1999). The use of gentamicinimpregnated poly $\{\mathrm{D}, \mathrm{L}\}$-lactide-co-glycolide and poly $\{\mathrm{D}, \mathrm{L}\}$-lactide disks eradicated staphylococcal infections from equine synovial membranes in vitro (Cook 1999). Plaster of Paris (PoP) is a commercially available and inexpensive material that has also been evaluated and used as a drug delivery system (DDS). This product consists mainly of calcium sulphate and its ability to release antibiotics has been shown to be a four-fold greater than that of PMMA (Bowyer 1994).

The in vitro elution of gentamicin, amikacin and ceftiofur from hydroxyapatite cement (HA) was compared with elution from PMMA, by researchers at the University of Florida (Ethell 2000). For all three antibiotics tested in that study, the rate of elution from HA beads was significantly greater than elution from PMMA. Gentamicin and amikacin concentrations were reported to remain above MIC for common susceptible 
pathogens for 30 days in the in vitro system used. Ceftiofur concentrations were sustained above MIC for susceptible pathogens for 7 days. This led the authors to conclude that ceftiofur-impregnated beads should not be used when long-term bactericidal concentrations are needed. To date, none of these biodegradable materials have been tested in animals in vivo, nor have there been reports of their clinical use for the treatment of equine orthopedic infections.

\section{Non-biodegradable drug delivery system (AIPMMA)}

History

Since first described in 1970 by Buchholz and Engelbrecht (Buchholz 1970), the mixing of antibiotics with PMMA for the treatment of localized infections, has been of considerable interest to orthopedic surgeons (Buchholz 1970; Calhoun 1989; Butson 1996; Tobias 1996; Ethell 2000; Henry 1991). Buchholz used AIPMMA to treat patients with infected total hip arthroplasties. This concept was then modified by Vidal and coworkers, who packed surgically debrided wounds with hand-made solid plugs of AIPMMA to treat patients with osteomyelitis. The AIPMMA was allowed to harden inside the debrided cavity. It was speculated that the exothermic reaction produced by polymerization may have contributed to the sterility of the wound. One out of seventeen cases was considered to have a poor result (Vidal 1969; Flick 1987). However, these

results were not replicated by Jenny et al, and Jenny and Taglang (Jenny 1977; Jenny 1979; Flick 1987). The solid plug concept was modified by Klemm, who fabricated AIPMMA into small spheres in the operating room before placement in the debrided cavity (Klemm 1977). The loose spheres were later tied together as bead chains (Flick 1987). Since 1976, gentamicin-impregnated PMMA beads have been commercially manufactured in Europe under the trade name of Septopal (Flick 1987). In 1977, Buchholz and coworkers reported on the prophylactic use of gentamicin-impregnated PMMA for various total hip arthroplasty procedures in humans; the infection rate was decreased from $5 \%$ in the control group to $0.8 \%$ in the gentamicin group (Buchholz 1977). Since then, it has been used extensively in both human and animal patients for the treatment and prevention of orthopedic infections. 


\section{General Concepts}

Polymethylmethacrylate, the major representative of the nonbiodegradable bone cements, is a commonly used drug delivery system (Buchholz 1970; Buchholz 1977; Henry 1991; Henry 1993; Schneider 1995; Butson 1996; Trostle 1996; Holcombe 1997). Polymethylmethacrylate can be impregnated with antibiotics and placed directly in the site of infection to increase local antibiotic concentrations (i.e. infected joints, tendon sheaths and fractures). In veterinary medicine, AIPMMA has been used for the treatment of infectious arthritis, osteomyelitis, infected fractures and fracture repair implants, infected wounds, incisional infections and chronic sinusitis in a cat (Schneider 1995; Butson 1996; Tobias 1996; Trostle 1996; Holcombe 1997). Placing AIPMMA composites at the site of infection, results in local release of high concentrations of antibiotic for extended periods of time. With the use of this treatment modality, tissue antibiotic concentrations up to 20 times higher than concentrations achieved using systemic antibiotics have been demonstrated (Henry 1991; Henry 1993). Localized, high concentrations of antibiotics facilitate the resolution of infections deeply imbedded in tissues (bone, synovium) that may otherwise be refractory to systemic antimicrobial therapy (Holcombe 1997). Several advantages of using this technique over systemic antibiotic therapy have been reported (Calhoun 1989; Henry 1991):

1) Higher tissue concentrations are achieved without the risk of organ toxicosis often associated with systemic antibiotic therapy. Serum and urine antibiotic concentrations have been found to be 10-20 times lower in patients treated with beads than in patients treated with systemic antibiotics (Henry 1991).

2) Serious complications have not been encountered.

3) Long-term intravenous catheters are not required.

4) Antibiotics may reach areas inaccessible to systemic antibiotics due to increased cellular debris or impaired blood supply.

5) This technique can be used in intractable patients where systemic administration is difficult or impractical.

6) It facilitates the use of drugs that may be too expensive for long-term systemic administration. 
7) It reduces the medical costs, particularly when a second surgery is not needed.

Another great advantage of the use of AIPMMA is the fact that it can be used to treat severely infected fracture fixation implants allowing implant preservation at the fracture site. In cases of infected fracture fixation implants, systemic antibiotics may be ineffective in the elimination of infection because certain bacteria produce a glycocalyx (extracellular biofilm), which shields them from systemic antibiotics and the phagocytic activity of inflammatory cells (Gristina 1984; Kanellakopoulou 2000). This biofilm, produced by organisms such as Stahylococcus aureus and Stahylococcus epidermidis, provides the bacteria with the capacity to adhere to the implants and survive on their surface. This stable adherence might provide a mechanism of recurrence of infection and development of resistance (Gristina 1984; Kanellakopoulou 2000). In light of these facts, the bacterial glycocalyx can potentiate infections around fracture fixation implants, necessitating removal of the implant for the infection to be resolved. Before the introduction of AIPMMA in veterinary medicine, removal of infected implants was necessary to resolve these infections (Schneider 1999). Although implant removal is still necessary in some cases, implant infections may be resolved by placing AIPMMA at the infection site. In a study where horses with infected fracture fixation implants were treated locally with AIPMMA, implant infection in 6 of 19 horses was eradicated without necessitating implant removal (Holcombe 1997). Antibiotic-impregnated PMMA facilitated resolution of infection in an open radial fracture, in a 15-year old, 9-monthpregnant mare (Schneider 1995). Antibiotic- impregnated PMMA has been suggested to be the best method of maximizing antibiotic concentrations locally at the site of infection (Schneider 1999).

The greatest disadvantage of using AIPMMA is that, it is non-absorbable and in some cases a second (potentially difficult) surgery is needed for AIPMMA implant removal (Kanellakopoulou 2000). Because of the potential difficulty associated with its removal, it has been recommended that AIPMMA should be removed within 14 days of implantation (Butson 1996). In some cases, removal has not occurred until 4 months after implantation (Henry 1993). In other cases, AIPMMA may be left in place permanently without complication (Henry 1993; Holcombe 1997). In one study, 6 of 19 
horses did not undergo bead removal and subsequent complications were not observed (Holcombe 1997). Henry et al. concluded that leaving beads in humans for prolonged periods of time was safe and correlated with a significant improvement in outcome (Henry 1993). When removal is required, rods or cylinders are reportedly easier to remove than beads (Holcombe 1997; Schneider 1999). Another disadvantage of using AIPMMA is the potential for the host to develop antibiotic resistance due to the lowlevel, prolonged exposure to the antibiotics (Calhoun 1989).

\section{Biomechanical Strength}

The addition of antibiotics to PMMA can affect the biomechanical strength of AIPMMA implants. When the biomechanical strength of an implant is important (e.g. total hip arthroplasty and plate luting), ratios of PMMA to antibiotic should not exceed 20:1 (Calhoun 1989; Tobias 1996). Addition of gentamicin powder to PMMA in a proportion of 20:1 did not significantly reduce the compressive strength of implants (Lautenschlager and Jacobs 1976; Ethell 2000). Incorporation of gentamicin powder in PMMA, in ratios of 10:1 or higher, was considered to result in strength reduction beyond what is recommended for weight bearing AIPMMA implants (Lautenschlager and Jacobs 1976; Ethell 2000). The addition of antibiotic solutions to PMMA significantly reduced its strength and delayed polymerization (i.e. its hardening) (Lautenschlager and Marshall 1976; Marks 1976; Goodell 1986). Marks et al. showed that the diametral tensile and compressive strengths of PMMA, combined with aqueous solutions of gentamicin, were significantly reduced compared with PMMA combined with the powdered form of gentamicin (Marks 1976). However, for use in applications where the biomechanical strength of the AIPMMA implant is not an important factor, PMMA-antibiotic ratios of up to 5:1 can be used (Cierny 1985). In one study, when volume ratios less than 5:1 (PMMA : antibiotic) were used, polymerization was not complete and hardening did not occur (Cierny 1985).

\section{Clinical Use in Large Animals}

Antibiotic-impregnated PMMA has been successfully used in the treatment of large animal orthopedic infections (Butson 1996; Trostle 1996; Holcombe 1997). 
Gentamicin-impregnated PMMA beads were used successfully in the treatment of refractory cases of infectious synovitis in 11 horses and 9 cattle. Six of the eleven horses returned to full athletic performance and all the cattle returned to their intended use (Butson 1996). In a retrospective study of horses with open or infected fractures and joints (10 long bone fractures, 2 comminuted phalangeal fractures, 5 joint injuries and 2 chronically septic joints), that were refractory to standard therapeutic strategies, AIPMMA was used for local delivery of antibiotics. In that study, the infection was resolved and bony union occurred in 15 of 19 horses. Gentamicin, amikacin, tobramycin and cefazolin were the antibiotics used in PMMA beads to treat those cases. The authors concluded that the use of AIPMMA should be considered for the treatment of open fractures and for acute and chronic bone and joint infections in horses (Holcombe 1997). An additional study indicated that metronidazole and cefazolin-impregnated beads aided in the treatment of infectious arthritis and osteomyelitis of the digit in a bull (Trostle 1996).

\section{Antimicrobial Selection}

Not all antibiotics are suitable for use in drug delivery systems (Popham 1991). Characteristics of ideal antibiotics for use in AIPMMA include (Popham 1991; Tobias 1996):

1) Release of high (bactericidal) concentrations of antibiotic initially and then sustained lower (bacteriostatic) concentrations for prolonged periods of time (Calhoun 1989).

2) Bactericidal action against bacterial pathogens most commonly encountered in the soft tissues and bony injuries that are being treated.

3) Exhibit a broad spectrum of activity.

4) Effective at low concentrations.

5) Elute from the matrix and result in concentrations exceeding MIC for most common pathogens.

6) Cause minimal soft-tissue toxicosis and allergic reactions.

7) Heat stability at body temperature $\left(37^{\circ} \mathrm{C}\right)$ and temperatures at which polymerization occurs (up to $100^{\circ} \mathrm{C}$ ). 
8) Water solubility to facilitate rapid elution.

Most of the literature concerning AIPMMA has focused on the use of gentamicinimpregnated PMMA beads. Gentamicin is commonly selected for its broad spectrum of activity, bactericidal activity, water solubility and heat stability. Furthermore, gentamicin-impregnated PMMA beads have been commercially available in Europe for the past two decades (Tobias 1996, Kanellakopoulou 2000). Gentamicin has been detected in wound fluid for up to 5 years after implantation of gentamicin-impregnated PMMA beads in human patients, but serum concentrations never exceeded $1.8 \mu \mathrm{g} / \mathrm{ml}$, even recently after implantation when wound exudate concentrations were $150 \mu \mathrm{g} / \mathrm{ml}$ (Wahlig 1980). In veterinary medicine, antibiotics most commonly used for preparation of AIPMMA include gentamicin, tobramycin, amikacin, cefazolin and cephalexin (Tobias 1996; Ethell 2000).

Anecdotal comments have been made suggesting that liquid antibiotics should not be used for preparation of AIPMMA (Welch 1978). However, Ethell et al. found no differences in elution patterns between beads made with liquid or powdered gentamicin. Similarly, no differences in rates of antibiotic elution were observed between PMMA beads made with $125 \mathrm{mg}$ of liquid or powdered amikacin. However, at $250 \mathrm{mg}$, PMMA beads with amikacin powder released greater amounts of antibiotic than beads made with amikacin solution. Nevertheless, the authors concluded that both liquid and powdered forms of gentamicin and amikacin could be used in AIPMMA clinically, because both preparations resulted in antibiotic concentrations above MIC for at least 30 days (Ethell 2000).

Antibiotics that have been shown not to elute from PMMA include colistimethate, polymixin B, tetracycline and choramphenicol (Picknell 1977; Calhoun 1989; Popham 1991). The lack of elution from PMMA may be due to the fact that they are not sufficiently heat stable and may not be able to retain activity after the exothermic polymerization reaction (up to $100^{\circ} \mathrm{C}$ ) (Calhoun 1989; Popham 1991; Kanellakopoulou 2000). Despite having little heat stability, penicillins have been shown to elute at acceptable concentrations (Picknell 1977; Bowyer 1994). In addition to penicillins, other antibiotics demonstrated to readily elute from PMMA include cephalosporins, 
aminoglycosides, fucidic acid, clindamycin, lincomycin and streptomycin (Picknell 1977; Popham 1991).

\section{Implant Preparation}

Antibiotic-impregnated PMMA implants can be manufactured sterilely at the time of surgery, or prepared preoperatively, sterilized and stored for later use. Currently, the recommended ratio of antibiotic to PMMA is 1-2 grams of the antibiotic powder per 4060 grams of PMMA (Calhoun 1989; Tobias 1996). Polymethylmethacrylate is commercially available in sterile packs of 20 and 40 grams. The PMMA powder should be mixed thoroughly with the antibiotic powder before the liquid monomer is added, in order to obtain a uniform elution. The AIPMMA is then transferred onto a bead mold to produce beads strung on suture material or surgical wire. Alternatively, the AIPMMA can be hand-rolled into any shape or size (more commonly beads or cylindrical implants). Once shaped, the AIPMMA implants are allowed to harden for 5-10 minutes (Kuechle 1991) before being placed in the surgical site or sterilized and stored. Implants of AIPMMA that are not used immediately can be sterilized with ethylene oxide and stored

for later use (Flick 1987; Butson 1996; Tobias 1996; Holcombe 1997). Ethylene oxide sterilization is preferable to steam autoclaving. Autoclaving creates humidity allowing some of the antibiotic to elute out of the beads during this process, making the autoclaved beads less potent than ethylene oxide-sterilized beads (Flick 1987). The high temperatures reached with the autoclave can render antibiotics ineffective, therefore antibiotics used for the preparation of AIPMMA, must be heat stable. Antibioticimpregnated PMMA implants, sterilized with ethylene oxide, should be aerated for at least 24 hours at room temperature or for a minimum of 8 hours in an aerator at $49^{\circ} \mathrm{C}$. This aeration technique ensures dissipation of ethylene oxide (Tobias 1996).

\section{Antimicrobial Elution}

Antimicrobial elution from PMMA occurs in a bimodal pattern. Rapid antibiotic release occurs during the first few days after implantation, with approximately $60-70 \%$ of the total antibiotic elution occurring during the first 24 hours. Thereafter, the rate of elution is slower and sustained for weeks, months or years (Wahlig 1980; Calhoun 1989; 
Henry 1991; Tobias 1996; Ethell 2000). This rapid release of antibiotic leads to high antibiotic concentrations spreading throughout the wound, which could potentially sterilize a previously debrided wound and its corresponding hematoma. As fibrous or bony tissue develops with time, the AIPMMA implant becomes encapsulated and confined to a smaller area within the wound, limiting the antibiotic release to an area of 2-3 $\mathrm{mm}$ in diameter. This situation may help maintain sterile conditions at the target site (Henry 1991).

The local tissue antimicrobial concentrations and length of time these concentrations remain above MIC after AIPMMA implantation depends on the ability of the specific antibiotic to elute from PMMA, among other things. Factors that affect the antimicrobial concentrations attained in local tissue include:

1) Type and porosity of the PMMA-

Greater rates of antibiotic elution have been obtained with Palacos (a commonly used brand of PMMA bone cement) compared with other brands of PMMA (Marks 1976; Picknell 1977; Goodell 1986; Henry 1991; Kuechle 1991). The differences in rates of elution between types of bone cement have been attributed to differences in pore sizes. The more porous the material is, the higher the rate of antibiotic elution (Goodell 1986; Flick 1987; Baker 1988; Henry 1991; Kuechle 1991). In one study, Kuechle and associates mixed AIPMMA with Dextran T70, 25\% by weight. The addition of Dextran to AIPMMA reportedly increased the porosity of the cement and the rate of antibiotic elution to the surrounding medium (Kuechle 1991). In that same study, AIPMMA beads prepared under negative atmospheric pressure (under a mixing chamber), which results in reduced porosity, had decreased antibiotic elution rates.

2) Surface area (roughness, size and shape) of the implant-

Elution rates are directly related to implant surface area. Greater amounts of antimicrobial are released from small, rough beads compared to large, smooth ones, because smaller and rougher beads have a greater surface area per volume of AIPMMA (Henry 1991; Tobias 1996). A sphere has more surface 
area per volume than does any other shape, therefore AIPMMA is most often formed into spheres (Henry 1991; Tobias 1996).

3) Amount of fluid flowing past the implant-

Local antibiotic tissue concentrations are inversely related to the amount of fluid flowing past the implant (Henry 1991; Tobias 1996). Highly vascularized tissue (e.g. muscle, granulation tissue) will absorb antibiotic into the body system faster than poorly vascularized tissue (e.g. scar, bone, infected/necrotic tissue). High vascularization results in lower tissue antimicrobial concentrations. Therefore, higher elution rates will be needed to maintain effective local antibiotic concentrations in highly vascularized tissues (Calhoun 1989; Tobias 1996).

4) Implant antimicrobial concentrations

The rate of antibiotic elution is directly related to the amount of antibiotic incorporated in the beads (Marks 1976; Tobias 1996; Ethell 2000). It has been demonstrated in vitro and in vivo that greater and longer-lasting antibiotic concentrations are achieved when the amount of antibiotic in the implant is increased. For example, the addition of $1.2 \mathrm{~g}$ compared to $2 \mathrm{~g}$ of gentamicin to $40 \mathrm{~g}$ of PMMA resulted in in vitro gentamicin concentrations above an in vivo established gentamicin MIC for 4 days (1.2g dose) compared to 28 days ( $2 \mathrm{~g}$ dose) respectively (Nelson 1992; Tobias 1996). The increased rate of elution with increased antibiotic concentrations has been suggested to result from increased porosity of the implants (Ethell 2000). The greater the amount of antibiotic in the composite, the rougher its surface is, the larger its surface pores are, as well as the channels from the surface into the bead (Calhoun 1989).

5) Antimicrobial diffusion properties-

Rates of elution of antibiotics from PMMA differ among antibiotics. The elution rates from PMMA, of aminoglycosides (gentamicin, amikacin, and tobramycin), vancomycin, cephalosporins (cefazolin, cephalothin and ceftiofur), penicillins, erythromycin, clindamycin, colistin sulfate, fusidic acid, and lincomycin have been evaluated (Popham 1991; Tobias 1996). In 
one study, the rates of elution of gentamicin, amikacin and ceftiofur from PMMA and hydroxyapatite cement (HAC) were evaluated in vitro. Both amikacin and gentamicin were released from PMMA at concentrations above MIC for at least 30 days, whereas ceftiofur concentrations fell below MIC after 7 days. Authors concluded that ceftiofur-impregnated PMMA or HAC beads are unlikely to provide long-term bactericidal concentrations (Ethell 2000).

\section{Mechanism of Drug Release}

The mechanism of drug release from PMMA is controversial. Some investigators suggest that the drug diffuses through the matrix of the cement (Schurman 1978), and others believe that it dissolves from the surface through holes or pores in the cement (surface dissolution) (Marks 1976). Bayston and Milner suggested that elution occurred as a consequence of antibiotic diffusion from an area of high antibiotic concentrations (inside the bead) to an area of low antibiotic concentrations (medium surrounding the bead) (Bayston 1982). Based on this theory, they speculated that in clinical situations, antibiotics may be released at a slower rate but over longer periods of time compared to in vitro conditions, which may have more fluid surrounding the beads. On the other hand, Baker and colleagues have provided evidence that antibiotic elution does not occur through diffusion (Baker 1988). In that study, diffusion chambers consisting of plain polymethylmethacrylate disks (without antibiotic) with diffusion tubes (made from short lengths of Pyrex tubing) were created. The inner compartment of the diffusion chamber was loaded with either gentamicin or methylene blue. The outer compartment contained a tissue-culture medium that was sampled monthly for 9 months and assayed for gentamicin or methylene blue. For gentamicin or methylene blue to be collected from the culture medium (outer chamber), it would have to have diffused from the inner chamber. Neither gentamicin nor methylene blue diffused through the disks at any time during the study period. As part of the same study, scanning electron microscopy confirmed the presence of craters, voids and cracks in the cement matrix of AIPMMA rods that had been placed in sheep (Baker 1988). The cracks may have served as conduits for

antibiotic elution. Taking in consideration the results of the in vitro and in vivo parts of 
the study, the authors concluded that the release of gentamicin from Palacos bone cement occurs from the surface of the cement and subsequently through a network of bubble-like voids and cracks in its matrix (Baker 1988).

\section{Advantages}

The greatest advantage of AIPMMA is the delivery of high concentrations of antibiotics in the local wound environment. Antibiotic concentrations in the woundfracture environment may be 20 times higher than the therapeutic levels in serum following systemic antibiotic therapy (Henry 1991; Henry 1993). Marks et al. found oxacillin concentrations of $52 \mu \mathrm{g} / \mathrm{g}$ in bone, 3 weeks after AIPMMA implantation; whereas, Kolczum et al. found only $7.6 \mu \mathrm{g}$ of oxacillin per gram of human bone after an intravenous infusion of 2 grams of oxacillin (Kolczum 1974; Marks 1976). Therefore, bacteria resistant to the low tissue antibiotic concentrations obtained after systemic administration may be susceptible to the high tissue concentrations obtained after local placement of AIPMMA implants (Henry 1991; Henry 1993). For this reason, standard reporting of antibiotic sensitivities and resistances, which are based on the highest, safest serum concentrations that can be obtained after systemic administration, may not be accurate for organisms treated with AIPMMA beads (Henry 1991; Henry 1993).

The amount and duration of the antibiotic release in vitro cannot be directly applied to an in vivo setting (Miclau 1993). The elution of the antibiotic from the bone cement may be affected by both the volume of the washings and the frequency with which the beads are bathed. If the volume of the washings is smaller in vitro than in vivo, then the antibiotic concentrations attained in vitro may be greater than in vivo (Miclau 1993). In vivo tissue concentrations may also vary, depending on the vascularity of the tissues, which will affect the rate of antibiotic absorption and clearance (Miclau 1993).

\section{Disadvantages and Complications}

The most common disadvantage associated with AIPMMA implants is the need for their removal. Local soft-tissue structures may be damaged during removal of AIPMMA, as it is made difficult by growth of fibrous tissue around these implants (Tobias 1996). As previously stated, AIPMMA has been left in place permanently in 
horses (Butson 1996; Tobias 1996; Holcombe 1997) and in humans without significant complications (Henry 1993). Furthermore, a study in humans has shown that patients who retained their AIPMMA permanently had significantly better outcomes than those who underwent surgery for removal. However, in some cases, permanent placement of AIPMMA results in infection attributed to these implants. In a study of 19 horses with orthopedic infection treated with AIPMMA, 1 horse developed wound infection and drainage 5 months and another one 3 years after all signs of infection had initially resolved. In both cases, draining tracts were followed to the AIPMMA implant and its removal resolved the infection (Holcombe 1997).

Allergic reactions associated with antimicrobials used in AIPMMA have not been reported (Tobias 1996). Ototoxicity and nephrotoxicity has not been found after longterm use of gentamicin-impregnated PMMA beads (Henry 1991; Henry 1993). In that study, renal deterioration was not detected for up to 2 years after gentamicin-impregnated PMMA implantation (Henry1991; Tobias 1996). In another study where tobramycinimpregnated beads were implanted in the hip of a 47-year-old woman, despite tobramycin wound fluid concentrations of $90 \mu \mathrm{g} / \mathrm{ml}$ collected during the first 24 hours, serum concentrations never exceeded $0.5 \mu \mathrm{g} / \mathrm{ml}$ and serum creatinine concentrations were unaffected (Goodell 1986). Furthermore, Henry et al. reported that serum gentamicin concentrations do not reach toxic levels, even when wound gentamicin concentrations were 10-50 times toxic serum levels (Salvati 1986; Calhoun 1989).

Methylmethacrylate (MMA) does not significantly alter immunoreactivity, (reactivity of immunoglobulins $\mathrm{A}, \mathrm{G}$, or $\mathrm{M}$ ) or the body's response to chemotactic factors produced by growing bacteria (Henry 1991; Tobias 1996). Methylmethacrylate does, however, have adverse effects on bacterial inhibiting factors, lymphocyte function, lateacting components of the complement sequence and bactericidal activity of leukocytes (Henry 1991). When MMA is allowed to polymerize inside the body, it leads to a release of small amounts of the liquid monomer into the vascular system. Clinical and experimental data suggest that these small amounts of MMA released during clinical use do not result in systemic toxicosis (Henry 1991). Polymethylmethacrylate may itself be cytotoxic to leukocytes if phagocytized and may inhibit DNA synthesis and cell growth. However, most of the adverse effects reported in the literature are associated with the use 
of methylmethacrylate (unpolymerized) and not with PMMA (polymerized), which is thought to be benign (Henry 1991; Tobias 1996).

As part of the indications for bead removal, Gristina (1990) has found that in the absence of sufficient antibiotic, PMMA can serve as a substratum for bacterial colonization and growth (Gristina 1990). In another study, Wilson et al. found several colonies of a tobramycin-resistant strain of Klebsiella present on the surface of one tobramycin-impregnated PMMA bead, 2 days before the bead ceased to leach antibiotic (Wilson 1988). In that study, the tobramycin bead was transferred daily onto a new agar plate streaked with fresh bacteria. Therefore, it was considered unlikely that the resistant bacteria arose within 24 hours of incubation subsequent to contamination during the experimental procedure, but more likely that small numbers of Klebsiella were being transferred successively on the surface of the bead and gradually mutated developing resistance to tobramycin (Wilson 1988).

\section{Antimicrobial Characteristics}

\section{Gentamicin Sulfate}

Gentamicin is an aminoglycoside antibiotic consisting of a combination of 4 components produced by Micromonospora purpurea, which are all, considered a single antimicrobial entity (Plumb 1995; Riviere 1995). Gentamicin sulfate occurs as a white powder with excellent water but poor lipid and alcohol solubility. Commercially available injectable preparations have a $\mathrm{pH}$ ranging from 3-5.5. Injectable gentamicin sulfate and oral solutions should be stored at room temperature $\left(15-30^{\circ} \mathrm{C}\right)$ and powdered preparations should be stored at $2-30^{\circ} \mathrm{C}$ (Plumb 1995).

Gentamicin is compatible (i.e. capable of being mixed with another drug without undergoing destructive chemical change or exhibiting mutual antagonism) with the following drugs: bleomycin sulfate, cefoxitin sodium, cimetidine hydrochloride, clindamycin phosphate, methicillin sodium, penicillin sodium, verapamil hydrochloride and metronidazole. Gentamicin is incompatible (i.e. should not be mixed with) with: amphotericin B, ampicillin sodium, cephalothin sodium, dopamine hydrochloride, furosemide and heparin sodium among other drugs (Plumb 1995). Gentamicin and other

aminoglycosides act by binding irreversibly to the $30 \mathrm{~S}$ subunit of the bacterial ribosome 
interfering with several mechanisms of mRNA translation process. Interference with the initiation of DNA replication may be responsible for its bactericidal effects. Gentamicin penetrates the bacterial cell membrane through an oxygen dependent process, which may explain anaerobic bacterial resistance to this antibiotic (Riviere 1995). Aminoglycosides are still considered the drugs of choice against aerobic, gram negative infections (Riviere 1995). Although routinely used parenterally in horses, gentamicin is only approved for intrauterine infusion in this species (Plumb 1995). Gentamicin, as other aminoglycosides, tends to accumulate in the inner ear and kidneys and is eliminated through glomerular filtration (Plumb 1995; Riviere 1995). The volume of distribution of gentamicin is larger in neonates and young animals because a large proportion of their body weight is extracellular fluid. Therefore, aminoglycoside induced nephrotoxicity is almost restricted to young animals and is rare in adults (Riviere 1995).

Gentamicin, along with other aminoglycosides, has good properties for use in PMMA (Popham 1991). Gentamicin is water soluble, heat stable, bactericidal at low concentrations, and has low antigenicity (Goodell 1986). In general, aminoglycosides are effective against microorganisms commonly cultured from orthopedic infections in horses (mostly gram negative aerobic bacteria) (Riviere 1995). A study in which the antimicrobial susceptibility of bacterial isolates from 233 horses with musculoskeletal infections was determined, revealed that gentamicin was effective against coagulase positive and negative staphylococci, Pseudomonas, Salmonella, Actinobacillus, E. coli and Klebsiella (Moore 1992). Since 1976, gentamicin has been incorporated in antibiotic-impregnated PMMA (Palacos ${ }^{\circledR}$ bone cement) beads and marketed in Europe under the trade name Septopal ${ }^{\circledR}$ (Popham 1991). These beads have been extensively used to treat osteomyelitis, bacterial arthritis, surgical infections and soft tissue infections. The release of gentamicin from PMMA is unaffected by environmental $\mathrm{pH}$, dependent on the surface area of the cement, and equal in either buffered saline or serum (Whalig 1980; Popham 1991). Gentamicin has been shown to elute from PMMA for up to 5 years (Wahlig 1980). 


\section{Metronidazole}

Metronidazole, a 1-2 hydroxyethyl-2-methyl-5-nitroimidazole, is a synthetic bactericidal agent used in human and veterinary medicine for the treatment of infections caused by obligate anaerobic bacteria and protozoa (Garber 1993). Metronidazole was first introduced in 1959 for the treatment of Trichomonas vaginalis infections in humans (Lindsay 1995). Its pure form occurs as cream to pale yellow crystalline powder or crystals that are soluble in water and ethanol but not in dilute acids (Lindsay 1995; Plumb 1995). It should be stored at temperatures less than $30^{\circ} \mathrm{C}$ and protected from light. Metronidazole base is available in tablet form, as a solution for IV injection, and metronidazole hydrochloride as a reconstituted powder for injection (Plumb 1995). Metronidazole is not approved by the FDA for use in veterinary medicine (Lindsay 1995; Plumb 1995).

Metronidazole is compatible with: amikacin sulfate, cefazolin sodium, cephalothin sodium, cefotaxime sodium, cefoxitin sodium, cefuroxime sodium, chloramphenicol sodium succinate, clindamycin phosphate, penicillin G sodium, tobramycin sulfate and gentamicin sulfate. It is incompatible with: aztreonan, cefamandole naftate and dopamine hydrochloride (Plumb 1995). Although its mechanism of action is not completely understood, it is believed that metronidazole is taken up by anaerobic bacteria where the drug is reduced to an unidentified polar compound that disrupts nucleic acid synthesis. Disruption of nucleic acid synthesis may explain its bactericidal activity against susceptible bacteria (Plumb 1995). Metronidazole is metabolized in the liver by oxidation and glucuronide formation and excreted by the kidneys. Small amounts are secreted in saliva and breast milk (Lindsay 1995). Potential complications attributable to metronidazole administration in humans are: glossitis, stomatitis, nausea, emesis and at high dosages (or subsequent to chronic moderate to high dosages), neurologic signs may occur (Lindsay 1995; Plumb 1995). In addition to these problems, dogs may exhibit weakness, neutropenias, hepatotoxicity, hematuria and diarrhea (Plumb 1995). Complications in horses are rare. In one study of 200 horses treated with metronidazole, only 4 horses $(2 \%)$ developed complications, which consisted of diminished appetite that resolved quickly after the drug was discontinued (Sweeney 1991). 
Metronidazole has been used successfully in horses for the treatment of respiratory infections (pleuropneumonia and lung abscesses); peritonitis; abdominal, umbilical and urachal abscesses; infectious arthritis; osteomyelitis; and cellulitis (Sweeney 1991; Garber 1993). Intravenous administration of metronidazole in large animals is usually impractical due to its expense. Metronidazole in horses is most commonly administered orally. In normal horses administered metronidazole orally at a loading dose of $15 \mathrm{mg} / \mathrm{kg}$ followed by $7.5 \mathrm{mg} / \mathrm{kg}$ (q $6 \mathrm{~h}$ ), mean trough concentrations in serum, peritoneal fluid, synovial fluid, endometrial fluid, spinal fluid and urine were $=4$ $\mu \mathrm{g} / \mathrm{ml}, 4.8 \mu \mathrm{g} / \mathrm{ml}, 5.1 \mu \mathrm{g} / \mathrm{ml}, 0.9 \mu \mathrm{g} / \mathrm{ml}, 4.3 \mu \mathrm{g} / \mathrm{ml}$ and $32 \mu \mathrm{g} / \mathrm{ml}$, respectively. These results demonstrate that except for its distribution to endometrial tissues, metronidazole is uniformly distributed throughout the body. Trough concentrations in all body tissues, except endometrium, exceeded the MIC for most common anaerobic pathogens in horses (Hirsh 1987; Snyder 1987). Metronidazole administration per rectum has also been evaluated. Rectal administration of this drug resulted in serum antibiotic concentrations higher than the reported MIC of $=2 \mu \mathrm{g} / \mathrm{ml}$ that was effective against $90 \%$ of Bacteroides spp and the $=4 \mu \mathrm{g} / \mathrm{ml}$ that was effective against Clostridium spp of animal origin (Hirsh 1987; Snyder 1987; Garber 1993). Although serum concentrations of metronidazole after rectal administration are greater than the reported MIC values for susceptible pathogens, they are markedly lower than concentrations achieved after oral and intra-gastric administration in horses (Garber 1993). Further studies are required to investigate the optimal dose and dosing interval for rectal administration of metronidazole. This route for metronidazole administration may be of value in horses, in which oral administration is impractical or results in anorexia. 


\section{MATERIALS AND METHODS}

\section{ELUTION STUdies}

\section{Fabrication of AIPMMA Beads}

Three strands of 0-braided, polyester suture material were pre-placed onto one half of a 6-mm diameter bead mold (Midwest Orthopedic Research Foundation, Orthopedic Biomechanics Laboratory, Minneapolis, MN). Powdered antibiotic and PMMA powder polymer (Surgical Simplex P Radiopaque Bone Cement; Howmedica Inc, Rutherford, NJ), were thoroughly hand-mixed for 1 minute at ambient temperature, using a plastic cup and a tongue depressor. Liquid monomer was added to the powder mixture (2:1 ratio of powder to liquid), was hand-mixed for approximately another minute, and the final product was transferred onto each half of the bead mold using the tongue depressor. The soft AIPMMA was spread throughout the mold and the mold clamps tightened. The PMMA without antibiotic and PMMA with incorporated gentamicin sulfate (Sigma, St. Louis, MO) were allowed to harden for approximately 10 minutes and the PMMA with incorporated metronidazole (Sigma, St. Louis, MO) was allowed to harden approximately 12 hours prior to removal from the bead mold. It took approximately 48 hours before metronidazole-impregnated beads completely hardened. Therefore, 48 hours were allowed before AIPMMA beads were used in the study. Excessive material was removed from the circumference of the beads making them approximately spherical and smooth. The weight of groups of ten beads each, minus the weight of the suture were determined using an analytical balance.

\section{Experimental Procedures}

The procedures used for the elution studies were similar to those previously reported (Picknell 1977; Miclau 1993; Bowyer 1994; Ethell 2000). The PMMAantibiotic mixtures were formulated based on a dry weight : weight ratio of PMMA polymer powder and antibiotic powder. The following groups were included in the elution studies: PMMA with metronidazole incorporated in 20:1 (MET 20:1), 30:1 (MET 30:1) and 40:1 (MET 40:1) ratios of PMMA to metronidazole, PMMA with gentamicin sulfate incorporated in a 20:1 PMMA to gentamicin sulfate ratio (GENT), and PMMA 
with metronidazole and gentamicin sulfate incorporated in a 20:1:1 ratio of PMMA, metronidazole and gentamicin sulfate (MET/GENT). A group of beads consisting solely of PMMA (without antibiotic) was eliminated from the elution studies after preliminary studies showed that detectable antibiotic did not elute from the beads and that eluent from PMMA did not interfere with analysis of metronidazole or gentamicin by high performance liquid chromatography (HPLC). For the antimicrobial bioactivity studies, the following groups were included in addition to the groups mentioned above: PMMA without antibiotic (PMMA), MET/GENT beads that were sterilized with ethylene oxide (EO) using routine technique and MET/GENT beads that were sterilized with ethylene oxide and stored for 2 months at room temperature (STORED). Solutions of metronidazole, $0.4 \mathrm{mg} / \mathrm{mL}$ (MET CONTROL) and gentamicin sulfate, $0.4 \mathrm{mg} / \mathrm{mL}$ (GENT CONTROL) were prepared and subjected to the same conditions of incubation and storage as the other groups. For each experimental group, two strands of 5 beads (10 beads total) or $2 \mathrm{mg}$ of antibiotic powder (MET CONTROL and GENT CONTROL) were placed in a $15-\mathrm{mL}$ conical tube containing $5 \mathrm{~mL}$ phosphate buffered saline (PBS) $\mathrm{pH}$ 7.4. Incubation was at $37^{\circ} \mathrm{C}$ with horizontal rotation at 25 cycles per minute. The beads were removed from the test tubes, allowed to air dry for 1 minute and transferred into a fresh-saline tube at 1, 3, 6, 12 and 24 hours (24-hour collection), or once daily for 21 days (daily collection). Different sets of beads were used for the 24-hour and daily sample collection methods. After the first 24 hours, the beads used for the 24-hour collection, were placed in fresh-saline tubes and samples collected weekly for 21 days (weekly collection). Each sample eluent was stored at $-70{ }^{\circ} \mathrm{C}$ until assayed. Experimental conditions were conducted in triplicate for each group and method of collection.

The percentage of antibiotic in the AIPMMA mixture was obtained by dividing the weight of the antibiotic powder by the weight of the AIPMMA mixture (PMMA powder polymer, liquid monomer and antibiotic powder) and multiplying by 100 . The mean percentage of metronidazole included in the AIPMMA mixture was $4.33 \%, 2.84 \%$, 2.17\% and 4.28\% for the MET 20:1, MET 30:1, MET 40:1 and MET/GENT groups respectively. The AIPMMA mixtures for the GENT and MET/GENT groups contained a mean $3.63 \%$ and $4.28 \%$ of gentamicin sulfate respectively. The mean amount of 
metronidazole present in 10 beads was $62,526 \mu \mathrm{g}, 40,019 \mu \mathrm{g}, 30,945 \mu \mathrm{g}$ and 59,360 $\mu \mathrm{g}$ for the MET 20:1, MET 30:1, MET 40:1 and MET/GENT groups respectively. The mean amount of gentamicin sulfate present in 10 beads was 60,398 $\mu \mathrm{g}$ and 59,338 $\mu \mathrm{g}$ for the GENT and MET/GENT groups respectively.

\section{Metronidazole Analysis}

The concentration of metronidazole in the sample eluent was determined by highperformance liquid chromatography (HPLC) using previously described methods (Venkateshwaran 1995). Each sample was filtered using a 13-mm diameter filter (Acrodisc ${ }^{\circ}$, Pall Gelman Laboratory, Ann Arbor, MI) with a $0.2 \mu \mathrm{m}$ pore size. Ten $\mu \mathrm{L}$ of the sample was injected onto a 30.0 x $4.6 \mathrm{~mm} \mathrm{C18}$ column (Econosphere ${ }^{\mathrm{TM}}$ Alltech, Deerfield, IL), with a $3 \mu \mathrm{m}$ particle size. The solvent used was a mixture of $85 \%$ methanol and $15 \%$ sodium phosphate buffer (0.01 M, pH 4.0) delivered at a flow rate of $1 \mathrm{~mL} / \mathrm{min}$ with UV detection at $313 \mathrm{~nm}$. A standard curve was generated using a stock solution of metronidazole dissolved in methanol. Appropriate dilutions of the stock solution were made using methanol to obtain the following concentrations of metronidazole: $0.1,0.25,0.5,1,5,10$ and $25 \mu \mathrm{g} / \mathrm{mL}$. The lowest limit of detection of metronidazole was $0.1 \mu \mathrm{g} / \mathrm{mL}$.

\section{Gentamicin Analysis}

The concentration of derivatized gentamicin in the sample eluent was determined by HPLC using previously described methods (Stead 1996; Stead 1997). Fifty $\mu L$ of the sample was mixed with $425 \mu \mathrm{L}$ of borate buffer $(0.2 \mathrm{M}, \mathrm{pH} 9.0)$ and $300 \mu \mathrm{L}$ of acetonitrile. The sample was treated with $200 \mu \mathrm{L}$ of a $2.5 \mathrm{mM}$ solution of 9fluorenylmethyl chloroformate in acetonitrile, for 15 minutes at $25{ }^{\circ} \mathrm{C}$. Twenty-five $\mu \mathrm{L}$ of $0.1 \mathrm{M}$ glycine in water was added and the mixture vortexed. The mixture was incubated at room temperature for 2 minutes. Ten $\mu \mathrm{L}$ of the derivatized sample was injected onto a 250 x $3.0 \mathrm{~mm} \mathrm{C18} \mathrm{(2)} \mathrm{column} \mathrm{(Luna}{ }^{\mathrm{TM}}$ Phenomex, Torrance, CA) with a $5 \mu \mathrm{m}$ particle size. The solvent was a mixture of acetonitrile (85\%) and water (15\%)

delivered at a flow rate of $1.5 \mathrm{~mL} / \mathrm{min}$. The derivatized gentamicin was detected by fluorescence with an excitation wavelength of $260 \mathrm{~nm}$ and an emission wavelength of 
$316 \mathrm{~nm}$. A standard curve was generated using a stock solution of gentamicin sulfate dissolved in distilled water and submitted to the same derivatization process as previously described for the samples. The lowest limit of detection of gentamicin was $0.1 \mu \mathrm{g} / \mathrm{mL}$.

\section{ASSESSMENT OF ANTIMICROBIAL BIOACTIVITY}

\section{Preparation of Test Solutions}

Two strands of 5 AIPMMA beads each were incubated for 5 days in $5 \mathrm{~mL}$ of PBS as previously described. The PBS was not changed during this time in order to obtain high antibiotic concentrations in the eluent, which was to be used later as a stock solution. Eluent from each group was passed through $0.2 \mu \mathrm{m}$ filters and aliquoted to sterile tubes. The concentration of metronidazole and gentamicin was determined as described previously. The eluent (stock solution) from the STORED group was only available for metronidazole bioactivity testing.

\section{Culture Methods}

The broth macrodilution method for determining the MIC of eluted antibiotics was conducted according to guidelines established by the National Committee for Clinical Laboratory Standards (NCCLS) for aerobic and anaerobic bacteria (ANSI 1991; ANSI 1999). Briefly, Bacteroides fragilis (ATCC \# 25285, Hardy Diagnostics, Santa Maria, CA) was incubated on an oxygen-reduced blood agar plate, under anaerobic conditions at $37{ }^{\circ} \mathrm{C}$ for 48 hours. Bacterial colonies were transferred into tubes of sterile water, vortexed, and the turbidity was adjusted to a 0.5 McFarland Standard (1.5 x $10^{8}$ CFU/mL) (Wilson 1988; ANSI 1991). Two-fold dilutions of eluted metronidazole (stock solution) were made in thioglycollate broth (Remel, Lenexa, KS), which was previously autoclaved to reduce its oxygen content. Two and one half milliliters of metronidazole/thioglycollate mixture was combined with $2.5 \mathrm{~mL}$ of the B. fragilis suspension and incubated under anaerobic conditions at $37{ }^{\circ} \mathrm{C}$ in a chamber equipped with a CO2 generator (Anaerogen ${ }^{\mathrm{TM}}$; Hardy Diagnostics, Santa Maria, CA), and an anaerobic indicator (Hardy Diagnostics, Santa Maria, CA) for 48 hours.

Escherichia coli (ATCC \# 25922, Hardy Diagnostics, Santa Maria, CA) was plated onto blood agar, and incubated at $37{ }^{\circ} \mathrm{C}$ for 24 hours under aerobic conditions. 
The resulting colonies were used to prepare a 0.5 McFarland Standard solution in sterile water. Two-fold dilutions of eluted gentamicin were made in Mueller-Hinton broth (Remel, Richmond, VA). One milliliter aliquots of gentamicin/Mueller-Hinton solution were mixed with $1 \mathrm{~mL}$ of the $E$. coli suspension and incubated under aerobic conditions at $37^{\circ} \mathrm{C}$ for 24 hours.

\section{Assessment of Bacterial Growth}

In addition to eluent from the MET 20:1, GENT, MET/GENT, EO, and STORED groups, the following groups were included as controls: PMMA eluent, uninoculated broth (contaminant control), inoculated broth without antibiotic (growth control), MET CONTROL, and GENT CONTROL solutions. The MIC for each group was determined using standard protocols. The MIC corresponded to the lowest antibiotic concentration yielding no growth as determined by visual assessment of change in the turbidity of the growth medium (Hirsh 1985, ANSI 1991; ANSI 1999). Additionally, an objective evaluation of bacterial growth was made by determining the optical density of each sample at the end of the incubation period using UV spectrophotometry (Beckman DU $640 \mathrm{~B}$ ) at $620 \mathrm{~nm}$ (Casciato 1975; Claus 1989). Uninoculated media was used as the sample blank.

\section{Statistical Analyses}

The elution of metronidazole and gentamicin was analyzed using the MIXED procedure of SAS (ver. 8.1, SAS Institute Inc., Cary, NC 27513). A repeated-measures analysis of variance was used to test for the main effects of metronidazole dose (MET 20:1, MET 30:1, MET 40:1) and treatment (MET 20:1 vs. MET/GENT or GENT vs. MET/GENT) and days of elution as well as their interaction. Significant interactions were further evaluated using Bonferroni-corrected, single-degree-of-freedom contrasts to compare doses on the same day. Spectrophotometric data were similarly analyzed testing

for the main effects of treatment group, concentration, or their interaction. Mean MIC was compared between treatment groups by ANOVA in a randomized complete block design using the GLM procedure of SAS. The level of significance was set at alpha = 0.05 . 


\section{RESULTS}

\section{ANTIMICROBIAL ELUTION}

\section{Elution of Metronidazole}

The elution of metronidazole was directly related to the amount of metronidazole incorporated in the AIPMMA beads (Figure 1). Results from the daily collection indicated that elution was greatest during the first 24 hours and accounted for a mean $63 \%, 66 \%$, and $65 \%$ of the 21-day cumulative elution of metronidazole for the MET 20:1, MET 30:1, and MET 40:1 groups respectively. Elution decreased abruptly during the second day and then continued to decrease gradually until day 7. Sustained, slowly decreasing elution of metronidazole was observed for the metronidazole-impregnated PMMA groups for the remainder of the 21 days. The MET 20:1 group released an average of $1846.6 \mu \mathrm{g}$ on day $1,303.5 \mu \mathrm{g}$ on day $2,38.6 \mu \mathrm{g}$ on day 7 and $23 \mu \mathrm{g}$ on day 21 . Similar patterns of elution were observed for the MET 30:1 and MET 40:1 groups (Figure 1). Throughout the study, metronidazole elution from the MET 20:1 group was significantly greater than for the MET 30:1 and MET 40:1 groups $(\mathrm{p}<0.05)$. Elution of metronidazole from the MET 30:1 group was significantly greater than for the MET 40:1 group for the first 7 days $(\mathrm{p}<0.05)$ but not thereafter. The mean cumulative elution of metronidazole after 21 days was $2927 \mu \mathrm{g}, 1664 \mu \mathrm{g}$, and $1093 \mu \mathrm{g}$, representing 4.68\%, $4.16 \%$ and $3.53 \%$ of the total amount of metronidazole incorporated into the AIPMMA beads for the MET 20:1, MET 30:1 and MET 40:1 groups, respectively.

The results of the 24-hour collection indicated that a cumulative mean $1708 \mu \mathrm{g}$, $1122 \mu \mathrm{g}$ and $880 \mu \mathrm{g}$ of metronidazole eluted from the MET 20:1, MET 30:1 and MET 40:1 groups respectively during the first 24 hours. A mean $49 \%, 51 \%$, and $51 \%$ of the metronidazole that eluted during the first 24 hours was eluted during the first hour for the MET 20:1, MET 30:1 and MET 40:1 groups respectively.

After 20 days of weekly sample collection (i.e. the 3 weeks included days 2-7, 814 and 15-21), a cumulative mean metronidazole elution of $1068 \mu \mathrm{g}, 413 \mu \mathrm{g}$ and $300 \mu \mathrm{g}$ was observed for the MET 20:1, MET 30:1 and MET 40:1 groups, respectively. Combining the data obtained from samples collected during the 24-hour and weekly collection periods, the cumulative mean metronidazole elution during the 21-day study 
period was $2776 \mu \mathrm{g}, 1535 \mu \mathrm{g}$ and $1180 \mu \mathrm{g}$ for the MET 20:1, MET 30:1 and MET 40:1 groups respectively. These results indicate that approximately $62 \%, 73 \%$ and $75 \%$ of the total metronidazole eluted (21 days) was released during the first 24 hours, for the MET 20:1, MET 30:1 and MET 40:1 groups, respectively. The cumulative metronidazole elution over 21 days was not significantly different $(\mathrm{p}=.7353)$ for the samples collected daily compared with those obtained from the combined 24-hour and weekly sample collections (Figure 2).

\section{Elution of Gentamicin}

The elution pattern of gentamicin for the GENT group was similar to that observed for the MET 20:1, MET 30:1 and MET 40:1 groups. A mean 79\% of the total gentamicin eluted from the GENT group throughout the study period was released during the first 24 hours. Elution of gentamicin from the GENT group resulted in a mean 1743.3 $\mu \mathrm{g}$ on day 1 and declined to $61.6 \mu \mathrm{g}$ by day 2 . Gentamicin elution remained relatively constant on days $2-6$, declined to a mean $13.3 \mu \mathrm{g}$ on day 7 and slowly decreased to $10 \mu \mathrm{g}$ by day 21 (Figure 3). The mean cumulative elution of gentamicin for the GENT group was $2208 \mu \mathrm{g}$, representing $3.66 \%$ of the gentamicin incorporated into the AIPMMA beads.

\section{Co-elution of Metronidazole and Gentamicin}

Gentamicin and metronidazole elution during the first 24 hours represented $67 \%$ and $33 \%$ respectively, of the 21-day cumulative elution. The elution pattern for gentamicin and metronidazole from MET/GENT beads was similar to that of other groups. Day 21 elution from the MET/GENT group was a mean $28.3 \mu \mathrm{g}$ gentamicin (Figure 3) and a mean $76.6 \mu \mathrm{g}$ metronidazole (Figure 4). The difference in rates of gentamicin and metronidazole elution for GENT, MET 20:1 and MET/GENT groups is depicted in figures 3 and 4 . The elution of gentamicin was significantly greater for the MET/GENT group than for the GENT group $(\mathrm{p}<0.05)$, throughout the study period. The elution of metronidazole was significantly greater for the MET/GENT group compared with the MET 20:1 group on days 3-21 ( $<<0.05)$ but was not significantly different on days 1 and 2. The total mean cumulative elution of metronidazole from the MET/GENT 
group $(4093 \mu \mathrm{g})$ was $40 \%$ greater than that obtained from the MET 20:1 group (2927

$\mu \mathrm{g})$. Similarly, the total mean cumulative elution of gentamicin from MET/GENT group $(4811 \mu \mathrm{g})$ was $118 \%$ greater than that obtained from the GENT group $(2208 \mu \mathrm{g})$.

\section{ANTIMICROBIAL BIOACTIVITY}

\section{Metronidazole Bioactivity}

Metronidazole was tested for bioactivity against $\beta$. fragilis in the concentration range from $0.125 \mu \mathrm{g} / \mathrm{mL}$ to $16 \mu \mathrm{g} / \mathrm{mL}$. Significant differences were not observed in the mean MIC of metronidazole from test solutions or compared with metronidazole from the MET CONTROL group $(\mathrm{p}=0.73)$. Pooling of the test solution data resulted in an overall mean metronidazole MIC of $2.26 \mu \mathrm{g} / \mathrm{mL}$. Significant differences were not observed in the inhibition of bacterial growth for metronidazole from any of the test solutions as assessed by spectrophotometric analysis of bacterial cultures ( $>0.05)$. Eluent from the PMMA group did not affect the growth of Bacteroides fragilis as compared with the growth control. Neither polymerization, combination with gentamicin, gas-sterilization, nor storage for two months at room temperature affected the bioactivity of metronidazole against Bacteroides fragilis (Figure 5).

\section{Gentamicin Bioactivity}

Gentamicin was tested for bioactivity against $E$. coli in concentrations ranging from $0.0625 \mu \mathrm{g} / \mathrm{mL}$ to $4 \mu \mathrm{g} / \mathrm{mL}$. Significant differences were not observed in the mean MIC of gentamicin from test solutions or compared with gentamicin from the GENT CONTROL group $(\mathrm{p}=0.80)$. Pooling of the test solution data resulted in an overall mean gentamicin MIC of $0.87 \mu \mathrm{g} / \mathrm{mL}$. Significant differences were not observed in the inhibition of bacterial growth for gentamicin from any of the test solutions as assessed by spectrophotometric analysis of bacterial cultures $(\mathrm{p}>0.05)$. Eluent from the PMMA group did not affect growth of E. coli as compared with the growth control. Neither polymerization, combination with metronidazole, nor gas-sterilization, affected the bioactivity of gentamicin against $E$. coli (Figure 6). 


\section{DISCUSSION}

Results of this study indicate that metronidazole elutes effectively from PMMA. These findings support the clinical observation on the use of metronidazole-impregnated PMMA beads in the treatment of refractory infectious arthritis and osteomyelitis of the digit in a bull (Trostle 1996). The elution of metronidazole persisted for 21 days in a uniform and dose-dependent manner as has been observed for other antibiotics incorporated in PMMA (Marks 1976; Baker 1988; Calhoun 1989; Miclau 1993; Ethell 2000). The pattern of elution of metronidazole and gentamicin from the AIPMMA beads was consistent with the observations of other investigators (Picknell 1977; Ethell 2000). Specifically, a relatively small percentage of the total incorporated metronidazole (mean $3.53 \%-4.68 \%$ for the three metronidazole groups) and gentamicin (mean 3.66\%) eluted from the PMMA beads containing these antibiotics individually. This finding was consistent with the cumulative elution of antibiotics from PMMA reported previously $(2.3 \%-11 \%)$, for a variety of penicillins, cephaloridine, clindamycin, sodium fusidate, and gentamicin (Picknell 1977). A large proportion (approximately 2/3) of the cumulative elution of antibiotics from PMMA in this study occurred during the first 24hour period, as previously reported for other antibiotics (Picknell 1977), and approximately one third of the total cumulative elution occurred during the first hour of incubation. This initial bolus release of antibiotic has been suggested to result from solvation of the fraction of antibiotic that is loosely adhered to the bead surface. Subsequent elution from deeper layers is suggested to result in reduced antibiotic concentrations over time (Picknell 1977; Baker 1988; Wilson 1988; Tripell 1986; Flick 1987).

PBS was used as the medium for antibiotic elution, because of successful results obtained with it in previous studies (Miclau 1993; Bowyer 1994; Ethell 2000). Due to its availability, phosphate buffered saline is more practical than serum for use in in vitro studies. Furthermore, antibiotic elution rates from PMMA have been found to be similar whether serum or PBS is used (Welch 1978; Wahlig 1980; Ethell 2000). The amount of PBS used to bathe the beads in vitro, as well as the amount of AIPMMA used for each sample was determined based on the results of a pilot study. The 5-ml of PBS used in 
this experiment is within the recommended range $(1-20 \mathrm{~mL})$ for use in elution studies (Ethell 2000). The time intervals, at which the PBS was changed in this study, are similar to those previously used in other studies (Picknell 1977; Miclau 1993; Ethell 2000; Bowyer 1994). A consistent daily collection method allowed us to know exactly when the elution rates decreased abruptly, and when they reached the plateau of sustained release. All samples for the elution experiments performed in this study were incubated at temperatures of $37^{\circ} \mathrm{C}$, similar to previous reports (Picknell 1977; Bowyer 1994; Ethell 2000). These temperatures are routinely chosen for elution studies to mimic in vivo conditions, since normal body temperature is approximately $37^{\circ} \mathrm{C}$. However, it has been proposed that temperature has little effect on rate of antibiotic elution from PMMA. This was suggested by Penner et al., who performed elution studies at room temperature $\left(21^{\circ} \mathrm{C}\right)$ in the search of project simplicity and their results were comparable to those obtained in other studies (Penner 1996).

The mean cumulative (21-day) elution of metronidazole did not vary significantly between the daily and the 24-hour/weekly collection methods. This finding implies that the frequency with which saline was changed in this study (21 times for the daily versus 8 times for the 24-hr/weekly collection methods), did not greatly affect the final amount of antibiotic eluting from the beads. This is not surprising, because the total amount of antibiotic that elutes from PMMA (in vitro) is small (less than 11\%) (Picknell 1977) and there is always a relatively large concentration gradient of antibiotic between the beads and PBS. This situation allows continued diffusion of the antibiotic into the surrounding medium and may partly explain the prolonged (5 years) release of gentamicin from PMMA in vivo (Wahlig 1980). However, as in all in vitro studies, the amount and duration of the antibiotic release in vitro cannot be directly extrapolated to an in vivo setting (Miclau 1993).

The co-polymerization of metronidazole and gentamicin into AIPMMA beads resulted in significantly higher eluent concentrations of both antibiotics than when either antibiotic was polymerized individually. The magnitude of the increase in day 21 elution for co-polymerization corresponded to a 3.3 fold increase in the elution of metronidazole and a 2.8 fold increase in elution of gentamicin. When the total cumulative antibiotic elution (total amount of antibiotic eluted through 21 days) is taken in consideration, there 
was a $40 \%$ increase in metronidazole elution and a $118 \%$ increase in gentamicin elution from the MET/GENT beads compared with the beads containing each antibiotic individually. These results support the findings of an earlier report indicating that a combination of tobramycin and vancomycin in bone cement improved the elution rate of each antibiotic by $68 \%$ and $103 \%$ respectively (Penner 1996), but are contrasted with the finding that combination of tobramycin and oxacillin resulted in increased elution of tobramycin but decreased elution of oxacillin (Tripell 1986). Kuechle et al. reported that elution rates that resulted from the combination of vancomycin and amikacin in PMMA were similar to rates obtained from AIPMMA with the antibiotics polymerized individually (Kuechle 1991). The effect on elution of combining two antibiotics into PMMA may depend on the antibiotics used, as well as the antibiotic concentration in PMMA (Tripell 1986). To our knowledge, no other study has evaluated the elution of two, equally-proportioned antibiotics incorporated into PMMA. In the present study, the amount of metronidazole and gentamicin in PMMA remained constant for the MET 20:1 and GENT groups compared with the MET/GENT group; as a consequence however, the overall ratio of PMMA to antibiotic powder was reduced from 20:1 to approximately 10:1. Perhaps, the increased elution of antibiotics from the MET/GENT group was attributable to increased porosity of the AIPMMA composite due to increased antibiotic content, as has been previously suggested (Marks 1976; Calhoun 1989; Kuechle 1991; Penner 1996). Similar mechanisms may be responsible for the dose-dependent increase in metronidazole elution observed in the present study and for other antibiotics in previous studies (Marks 1976; Baker 1988; Calhoun 1989). In addition to the benefit of improved rates of elution, a combination of two antibiotics in AIPMMA beads should result in an improved antibiotic spectrum (Penner 1996).

In the study reported here, AIPMMA beads were formed on strands of 0 -braided, polyester suture material. Compared to monofilament, braided suture materials offer increased friction (Gupta 1985) between the bead and the suture, preventing bead slippage that may lead to incomplete or difficult bead removal. Since PMMA beads are non-absorbable, they often necessitate a second surgery for bead removal (Calhoun 1989; Kanellakopoulou 2000), which typically takes place 2-4 weeks after implantation (Cierny 1985; Kanellakopoulou 1989; Henry1993). Long term placement of AIPMMA beads 
may result in trauma to surrounding tissues and lead to pain (Farnsworth 2001), adding to the importance of bead removal. In cases where the surgery for bead removal is delayed for long periods of time, it may be easier to remove beads incorporated onto nonabsorbable suture material because if the absorbable suture material disintegrates, the beads could become loose in a body cavity. A major disadvantage of using braided suture material for bead fabrication is that braided sutures can potentiate infections (compared with monofilament materials) (Katz 1981; Osterberg 1983; Scher 1985). Bacteria in the interstices of multifilament sutures, protected from the phagocytic activity of leukocytes, may perpetuate infections (Osterberg 1983). Based on these facts, fabrication of AIPMMA beads incorporated onto monofilament suture materials may be more appropriate for clinical application. Alternatively, stainless steel wire can be used for bead fabrication (Flick 1987; Henry 1993; Butson 1996; Holcombe 1997). Stainlesssteel surgical suture wire causes little tissue reaction and is monofilament. Antibioticimpregnated PMMA beads fabricated with stainless-steel wire have been used with success in the treatment of equine orthopedic infections (Butson 1996; Holcombe 1997).

The ratio of PMMA to antibiotic recommended for use in experimental studies and clinical settings, where the biomechanical properties of AIPMMA is important, has ranged from 20:1 to 60:1 (Calhoun 1989; Tobias 1996). Biomechanical studies on AIPMMA have indicated that for implant fixation (total joint arthroplasty), antibiotics should comprise no more than $10 \%$ of the AIPMMA composite weight (a 10:1 ratio of PMMA to antibiotic) (Calhoun 1989). For bead fabrication however, where the biomechanical characteristics of AIPMMA are not as important, it has been suggested that ratios up to 5:1 (PMMA to antibiotic) may be used without significant impairment of polymerization (i.e. hardening of the beads) (Cierny 1985). The highest antibiotic dose used for AIPMMA preparation in our study was approximately a 10:1 ratio, for the MET/GENT group.

Hardening of AIPMMA beads typically occurs in 5 to 10 minutes after addition of the liquid monomer (Goodell 1986). Interestingly, we found that even at very low antibiotic doses (100:1), metronidazole prolonged the polymerization of AIPMMA to approximately 48 hours (data not presented). After 48 hours, there was no grossly 
appreciable difference in the hardness of the beads with or without metronidazole. However, it was beyond the scope of this study to test the biomechanical characteristics of metronidazole-impregnated PMMA. Delayed polymerization is peculiar to metronidazole powder, as we are unaware of any other antibiotic powder reported to cause this effect on PMMA. Aqueous solutions of antibiotic can cause delayed polymerization. Marks and coworkers reported that both gentamicin solution and water, in concentrations as little as 4 milliliters per $40 \mathrm{~g}$ batch of PMMA, prolonged the set time, and altered the doughing characteristics of the cement so that it never passed through the sticky stage ( Marks 1976). Oxacillin powder, on the other hand, added to PMMA at a ratio of 1:5 did not affect polymerization (Marks 1976). Higher metronidazole amounts could potentially be incorporated into PMMA to obtain greater rates of elution, but further study is necessary to evaluate the maximum concentration of metronidazole that would result in acceptable polymerization of AIPMMA.

We believed that since the incorporation of metronidazole dramatically reduced the rate of polymerization of AIPMMA, it was possible that the antibacterial activity of the eluted metronidazole from the AIPMMA composite could have been altered. Additionally, to our knowledge, the antibacterial activity of antibiotics co-polymerized and co-eluted from AIPMMA has not been reported previously. Bacteroides fragilis and E. coli were chosen to test the bioactivity of eluted metronidazole and gentamicin, respectively, in accordance with the NCCLS guidelines for the determination of MIC of metronidazole and gentamicin (ANSI 1991; ANSI 1999). These organisms are also commonly isolated from clinically relevant equine infections (Adamson 1985; Hirsh 1985; Sweeney 1986; Hirsh 1987; Kanoe 1988; Sweeney 1991; Moore 1992; Schneider and Moore 1992; Moore 1993a). Bacteroides fragilis is the member of the Bacteroides genus most commonly found to produce the B-lactamase enzyme, responsible for resistance to B-lactam antibiotics (Hirsh 1985; Sweeney 1986).

The results of our metronidazole bioactivity study indicate that the MIC of metronidazole was $2 \mu \mathrm{g} / \mathrm{ml}$. This MIC is one fold higher than the MIC reported in the NCCLS guidelines for Bacteroides fragilis (0.25 - $1 \mu \mathrm{g} / \mathrm{ml}$ ) (ANSI 1991). Two factors could have possibly contributed to the higher MIC observed in our study: 1) the bottle of 
metronidazole was approximately 14 months old by the time the study was performed. Although this form of metronidazole has a shelf life of 2-3 years, it is possible that the antibiotic had lost some of its efficacy. 2) The media used in this study to support bacterial growth was not the one used to establish the NCCLS guidelines. Controversy exists concerning the MIC testing for anaerobic bacteria even in humans (ANSI 1991). The NCCLS guidelines are established for the interpretation of susceptibility values of human bacterial isolates. The lack of guidelines, concerning drug disposition in animal patients, further complicates interpretation of MIC values. The goal of this study was not to determine MIC values for the antibiotic, but to determine if bioactivity changed for any of the groups evaluated.

Mueller-Hinton broth was used as the growth media for E. Coli, as recommended by the NCCLS guidelines (ANSI 1999). Brain-heart infusion (BHI) broth is a medium recommended by the NCCLS guidelines to be used for growth of Bacteroides fragilis. However, in our hands, BHI failed to provide consistent results. Instead, thioglycollate was used for growth of Bacteroides fragilis. Thioglycollate, although not recommended by the NCCLS guidelines, has been extensively used for growth of anaerobic bacteria (Dankert 1980; Hunt 1982). Thioglycollate is a commercially available, oxygen-reduced broth that contains an anaerobic indicator that changes color in the presence of oxygen. This feature allowed us to assure that the medium remained anaerobic throughout incubation.

Gram-negative organisms, including Pseudomonas aeruginosa, E. coli, Enterobacter aerogenes and other Enterobacteriaceae, have been shown to develop adaptive resistance against gentamicin and other aminoglycosides (Daikos 1990; Barclay 1992; Karlowsky 1997; Barclay 2001). Aminoglycoside adaptive resistance is defined as reduced antimicrobial killing in originally susceptible bacterial populations, after the initial antimicrobial dose (Karlowsky 1997; Barclay 2001). This form of resistance, which develops within 1 to 2 hours of initial antibiotic exposure, is enhanced by the continued presence of the drug and is reversed after several hours of growth in a drug free environment (Daikos 1990; Barclay 1992; Barclay 2001). The duration of resistance is directly related to the elimination half-life of the aminoglycoside. In humans, maximum 
resistance occurs for up to 16 hours after a single dose, decreases to partial resistance at 24 hours and completely recovers by 40 hours (Barclay 2001). Therefore, administration of aminoglycosides at 24-hour intervals or longer has been advocated to increase treatment efficacy by allowing time for adaptive resistance to be reversed (Barclay 2001). Aminoglycoside-impregnated PMMA beads could enhance bacterial resistance by providing sustained, low antibiotic levels after initial high tissue concentrations (Tripell 1986; Baker 1988; Wilson 1988; Calhoun 1989). Development of resistance may be more likely to occur in cases where bacteria survive the initial, high antibiotic concentrations or where there is continued bacterial exposure (open wounds). Bacteria resistant to low serum antibiotic concentrations, like the concentrations attained in the previously mentioned studies during induction of bacterial adaptive resistance (Daikos 1990; Barclay 1992), may be susceptible to the high tissue concentrations achieved with the use of AIPMMA (Henry 1991; Henry 1993). Subsequently, conventional antimicrobial sensitivity testing may not be clinically applicable for bacteria subjected to AIPMMA beads (Henry 1991; Henry 1993). Furthermore, improved outcomes and fewer complications have been observed in human patients who retained their AIPMMA implants, as opposed to those who underwent surgery for implant removal (Henry 1993). In most cases, the benefits associated with the use of AIPMMA implants will outweigh their risks (Tripell 1986).

Our research study supported the previous finding that PMMA alone has no appreciable inherent antibacterial components that elute under the conditions of our study (Marks 1976; Picknell 1977; Calhoun 1989). Our findings also support the concept, that antibiotics eluted from PMMA retain their antibacterial activity (Marks 1976; Picknell 1977; Wilson 1988; Kuechle 1991). It has been shown previously that gas-sterilization of AIPMMA with ethylene oxide does not adversely affect the activity of selected antibiotics (Flick 1987). Furthermore, horses have been successfully treated for localized infections with AIPMMA beads that had been gas-sterilized and stored (Butson 1996; Holcombe 1997). Our results indicated that the antibacterial activity of neither metronidazole nor gentamicin, incorporated into PMMA individually or in combination was affected by polymerization, or by ethylene oxide sterilization (Figures 5 and 6). In addition, storage of MET/GENT beads (at room temperature for up to 2 months) did not 
adversely affect the antibacterial activity of eluted metronidazole. Although eluent from the 2-month stored MET-GENT group was not available for gentamicin bioactivity testing in the current study, successful clinical applications of gas-sterilized and stored gentamicin-impregnated PMMA beads have been reported in horses previously (Butson 1996; Holcombe 1997). A weakness of the previously cited, clinical case reports is the absence of control populations necessary for critical evaluation of efficacy of AIPMMA treatment of infection. Nevertheless, our results, along with the subjective improvement of large animals treated with AIPMMA in these clinical case reports, suggest that it would be feasible to fabricate, sterilize, and store metronidazole/gentamicin-impregnated beads for later use. This finding is important in light of the slow rate of polymerization of PMMA containing metronidazole.

The MIC values established for metronidazole using anaerobic bacteria isolated from horses indicate that a metronidazole concentration of $4 \mu \mathrm{g} / \mathrm{mL}$ should be effective against $97 \%$ of Bacteroides species and 100\% of Fusobacterium necrophorum (Hirsh 1987). These anaerobic isolates are reported to commonly affect horses (Kanoe 1988; Moore 1993a). Another study of 823 veterinary clinical specimens shows that all isolated obligate anaerobes including B. fragilis are susceptible to metronidazole (Hirsh 1985). Gentamicin sulfate is a broad spectrum antibiotic frequently selected, based on culture and sensitivity or empirically, for the prophylaxis and treatment of gram-negative infections in horses. Gentamicin is an effective antibiotic against coagulase-positive and coagulase-negative staphylococci, Pseudomonas, Salmonella and Actinobacillus isolated from horses (Moore 1992). Furthermore, bacterial isolates such as Actinobacillus spp., Staphylococcus spp., Salmonella typhimurium, and E. coli are susceptible to gentamicin sulfate concentrations of $=2 \mu \mathrm{g} / \mathrm{mL}$ (Adamson 1985; Hirsh 1987). Synovial fluid concentrations of gentamicin $=2 \mu \mathrm{g} / \mathrm{mL}$ are sustained for 9 days, following implantation of one hundred and twenty, $3.2 \mathrm{~mm}$ diameter gentamicin sulfate-impregnated PMMA beads, into the tarsocrural joint of horses (Farnsworth 2001). In the current study, the elution of antibiotic from ten 6-mm MET/GENT beads had decreased to a mean of 76.5 $\mu \mathrm{g}$ of metronidazole and $28 \mu \mathrm{g}$ of gentamicin by day 21 , indicating that sustained elution is feasible. It is tempting to extrapolate our results to clinically relevant issues such as the development of minimum inhibitory concentrations; however, such conclusions 
would not have merit. In this study, elution was reported in $\mu \mathrm{g}$ rather than $\mu \mathrm{g} / \mathrm{mL}$ to avoid this potential confusion. The local concentration of antibiotics in clinical applications of AIPMMA would be influenced by the half-life of the antibiotic, the apparent volume of distribution and the rate of clearance of the antibiotic from the local environment. Pharmacokinetic data for the specific applications of AIPMMA are needed to determine the duration of biologically relevant concentrations, resulting from clinical application of AIPMMA delivery of metronidazole and gentamicin. Factors such as bead diameter and number, or antibiotic concentration could be varied to influence antibiotic concentration and duration, resulting from the use of AIPMMA in clinical applications.

The mechanism of drug release from PMMA is controversial. Some investigators suggest that drugs diffuse through the matrix of the cement, and others that it dissolves from the surface through holes or pores in the cement (surface dissolution) (Marks 1976; Schurman 1978). Bayston and Milner have suggested that elution occurred as a consequence of antibiotic diffusion from an area of high antibiotic concentrations (inside the bead) to an area of low antibiotic concentrations (medium surrounding the bead). Accordingly, they concluded that in clinical situations, antibiotics may be released at a slower rate but over longer periods of time compared to in vitro conditions, which may have more fluid surrounding the beads (Bayston 1982). Results of this and other in vitro studies refute this theory because no more than $11 \%$ of the total antitbiotic incorporated was released from PMMA (Picknell 1977). This means that 95\% of the antibiotic did not elute, so there was always more antibiotic in the bead than in the outside medium, which should favor continued concentration gradient driven diffusion. Results of our study showed that the frequency of the washings (new saline changed in daily versus 24hr/weekly samples) had no impact on the cumulative amount of antibiotic released from PMMA. This implies that the antibiotic concentration in the bead never equals that of the surrounding medium, which should favor a greater and more prolonged antibiotic diffusion from the beads into the surrounding medium. This however is not the case, since PMMA releases 5-11\% of the antibiotic and then it gradually decreases until it approaches zero. The highest percentage of antibiotic reported to have eluted from PMMA, in the literature, is $11 \%$ of the total amount of antibiotic included in the beads (89\% of the antibiotic remained in the beads) (Picknell 1977). 
Clindamycin and lincomycin have a very similar spectrum of activity and provide antibacterial concentrations when eluted from the Palacos brand of bone cement. Of these two antibiotics, clindamycin is generally more active and has been used to treat chronic bone infections caused by staphylococci in humans. Picknell et al. reported that $68 \%$ of the clindamycin eluted during a 4-day period was released within the first 24 hours (Picknell 1977). Clindamycin, compared with 10 other antimicrobials eluting from PMMA, was the most effective and maintained a zone of inhibition for 80 days on culture plates inoculated with staphylococci (Levin 1975; Popham 1991). Both clindamycin and lincomycin can be used to treat mixed infections involving anaerobic bacteria or in patients with poor vascular supply to the extremities (Popham 1991). Because of its spectrum of activity and its ability to elute from PMMA, clindamycin is a good choice for incorporation in PMMA to treat anaerobic infections (Picknell 1977; Popham 1991). Clindamycin-impregnated PMMA could potentially be used for the treatment of orthopedic infections in horses caused by anaerobic bacteria. However, metronidazoleimpregnated PMMA beads could be safer to use in horses since metronidazole is commonly used systemically in this species to treat anaerobic infections, whereas clindamycin is not used in horses due to potential development of fatal colitis. Furthermore, clindamycin elutes poorly after 4 days (Picknell 1977). Although it is not appropriate to compare elution rates between studies due to differences in experimental protocols, it is possible that metronidazole could have better elution properties than clindamycin. Further studies are needed to evaluate the in vivo effects of metronidazole or clindamycin-impregnated PMMA implantation in horses. 


\section{CONCLUSION}

Metronidazole and gentamicin incorporated individually or in combination, eluted from PMMA effectively and at gradually decreasing rates for at least 21 days. The frequency at which the bathing solution (PBS) is changed did not affect the degree of antibiotic elution from PMMA in vitro. The co-polymerization of metronidazole and gentamicin in PMMA improved the rate of elution of both antibiotics, under the conditions evaluated in this study. Metronidazole/gentamicin-impregnated PMMA beads may be fabricated, sterilized using ethylene oxide and stored for up to 2 months preceding use, without adversely affecting efficacy. The effects of PMMA impregnated with metronidazole and gentamicin on surrounding soft tissues and the pharmacokinetic behavior of these antibiotics should be evaluated in vivo to guide recommendations for specific clinical applications. 


\section{LITERATURE CITED}

Adamson PJW, Wilson WD, Hirsh DC, et al.: Susceptibility of equine bacterial isolates to antimicrobial agents. Am J Vet Res 46:447-450, 1985

ANSI. Methods for antimicrobial susceptibility testing of anaerobic bacteria (ed 2). National Committee for Clinical Laboratory Standards M11-A2 10:1-23, 1991

ANSI. Susceptibility tests for bacteria isolated from animals. National Committee for Clinical Laboratory Standards M31-A 19:16-25, 1999

Baker AS, Greenham LW: Release of gentamicin from acrylic bone cement: elution and diffusion studies. J Bone Joint Surg [Am] 70-A:1551-1557, 1988

Barclay ML, Begg EJ: Aminoglycoside adaptive resistance: importance for effective dosage regimens. Drugs 2001 61:713-721, 2001

Barclay ML, Begg EJ, Chambers ST: Adaptive resistance following single doses of gentamicin in a dynamic in vitro model. Antimicrob Agents Chemother 36:1951-1957, 1992

Bayston R, Milner RDG: The sustained release of antimicrobial drugs from bone cement. J Bone Joint Surg [Br] 64:460-464, 1982

Bowyer GW, Cumberland N: Antibiotic release from impregnated pellets and beads. $\underline{\mathbf{J}}$ Trauma 36:331-335, 1994

Buchholz HW, Englebrecht H: Uber die Depotwirkung einiger Antibiotica bei Vermischung mit dem Kunstharz Palacos. Der Chirurg 11:511-515, 1970 
Buchholz HW, Engelbrecht E, Rottger J, et al.: Erkentnisse nach Wechsel von uber 400 infizierten Huftendoprosthesen. Orthop Prax 12:1117-1120, 1977

Butson RJ, Schramme MC, Garlick MH, et al.: Treatment of intrasynovial infection with gentamicin-impregnated polymethylmethacrylate beads. Vet Rec 138:460-464, 1996

Calhoun JH, Mader JT: Antibiotic beads in the management of surgical infections. Am J Surg 157:443-448, 1989

Casciato DA, Stewart PR and Rosenblatt JE: Growth curves of anaerobic bacteria in solid media. Appl Microbiol 29:610-614, 1975

Cierny GIII, Mader JT, Penninck JJ: A clinical staging system for adult osteomyelitis. Contemp Orthop 10:17-37, 1985

Claus GW: Understanding microbes (ed). New York, NY, W.H. Freeman, 1989, pp 167174

Cook VL, Bertone AL. Infectious arthritis, in N. A. White II and J. N. Moore (2 ed): Current techniques in equine surgery and lameness (2 ed). Philadelphia, PA, W.B. Saunders Company, 1998, pp 381-385

Cook VL, Bertone AL, Kowalski JJ et al.: Biodegradable drug delivery systems for gentamicin release and treatment of synovial membrane infection. Vet Surg 28:233-241, 1999

Daikos GL, Jackson GG, Lolans VT, et al.: Adaptive resistance to aminoglycoside antibiotics from first-exposure down-regulation. The Journal of Infectious Diseases $162: 414-420,1990$ 
Dankert J, Holloway Y, Schaareman M: A new anaerobic blood culture medium: Laboratory Evaluation. Zentralbltt for Bakteriologie 248:392-401, 1980

Eitenmuller J, Schmidt K, Peters G, et al.: Experimental and preliminary clinical experience with absorbable calcium phosphate granules containing an antibiotic or antiseptic for the local treatment of osteomyelitis. J Hosp Infect 6:177-184, 1985

Ethell MT, Bennett RA, Brown MP, et al.: In vitro elution of gentamicin, amikacin and ceftiofur from polymethylmethacrylate and hydroxyapatite cement. Vet Surg 29:375382,2000

Farnsworth KD, White II NA, Robertson J: The effect of implanting gentamicinimpregnated polymethylmethacrylate beads in the tarsocrural joint of the horse. Vet Surg 30:126-131, 2001

Flick AB, Herbert JC, Goodell J, et al.: Non-commercial application of AIPMMA beads. Technical note. Clin Orthop Rel Res 223:282-286, 1987

Garber JL, Brown MP, Gronwall RR, et al.: Pharmacokinetics of metronidazole after rectal administration in horses. Am J Vet Res 54:2060-2063, 1993

Gibson KT, Mcllwraith CW, Turner AS, et al.: Open joint injuries in horses: 58 cases (1980-1986). J Am Vet Med Assoc 194: 398-404, 1989

Goodell JA, Flick AB, Hebert JC, et al.: Preparation and release characteristics of tobramycin-impregnated polymethylmethacrylate beads. Am J Hosp Pharm 43: 14541461, 1986

Gristina AG, Costerton JW.: Bacterial adherence and the glycocalyx and their role in musculoskeletal infection. Orthop Clinics North Am 15:517-535, 1984 
Gristina AG, Naylor PT, Webb LX.: Molecular mechanisms in musculo-skeletal sepsis: The race for the surface. Instructional course lectures 39:471-482, 1990

Gupta BS, Wolf KW, Postlethwait RW: Effect of suture material and construction on frictional properties of sutures. Surg Gynecol Obstet 161:12-16, 1985

Henry SL, Hood GA, Seligson D: Long-term implantation of gentamicinpolymethylmethacrylate antibiotic beads. Clin Orthop Rel Res 295:47-53, 1993

Henry SL, Seligson D, Mangino P, et al.: Antibiotic-impregnated beads, Part 1: Bead implantation versus systemic therapy. Orthop Rev 20:242-247, 1991

Hirsh DC, Indiveri MC, Jang SS: Changes in prevalence and susceptibility of obligate anaerobes in clinical veterinary practice. J Am Vet Med Assoc 186:1086-1089, 1985

Hirsh DC, Jang SS: Antimicrobic susceptibility of bacterial pathogens from horses. Vet Clin North Am Equine Pract 3: 181-190, 1987

Holcombe SJ, Schneider RK, Bramlage LR, et al.: Use of antibiotic-impregnated polymethylmethacrylate in horses with open or infected fractures or joints: 19 cases (1987-1995). J Am Vet Med Assoc 211:889-893, 1997

Hunt GH, Price E: Comparison of a homemade blood of liver, with four commercially available media for the paediatric blood cultures. J Clin Pathol 35:1142-1149, 1982

Jenny G, Kempt J, Jaeger JH, et al.: Utilisation de billes de ciment acrylique a la gentamycine dans le traitement de l'infection oseouse. Rev Chir Orthop 63:491, 1977

Jenny G, Taglang G: Traitement local de l'infection osseuse par des billes de ciment acrylique a la gentamycine. Acta Belg Med Phys 45:57, 1979 
Kanellakopoulou K, Giamarellos-Bourboulis EJ: Carrier systems for the local delivery of antibiotics in bone infections. Drugs 2000 59:1223-1232, 2000

Kanoe M, Hirabayashi T, Anzai T, et al.: Isolation of obligate anaerobic and some other bacteria from equine purulent lesions. Br Vet J 144:374-378, 1988

Karlowsky JA, Zelenitsky SA, Zhanel GG: Aminoglycoside adaptive resistance. Pharmacotherapy 17:549-555, 1997

Katz S, Izhar M, Mirelman D: Bacterial adherence to surgical sutures. A possible factor in suture induced infection. Ann Surg 194:35-41, 1981

Klemm, K: Die behanlung chronisher knocheninfektionen mit Gentamycin-PMMAKetten und -Kugelin, in H. Contzen (ed.): Gentamycin-PMMA-Ketten. GentamycinPMMA-Kugelin. Symposium Munchen, November 12, 1976. Erlanger, Federal Republic of Germany, VLE Verlag, 1977, p.20

Kolczun MC, Nelson CL, McHenry MC, et al.: Antibiotic concentrations in human bone, a preliminary report. J Bone and Joint Surg. 156-A: 305-309, March, 1974

Kuechle DK, Landon GC, Musher DM, et al.: Elution of vancomycin, daptomycin, and amikacin from acrylic bone cement. Clin Orthop Rel Res 264:302-308, 1991

Lautenschlager EP, Jacobs JJ, Marshall GW, et al.: Mechanical properties of bone cements containing large doses of antibiotic powders. J Biomed Mater Res 10:929-938, 1976

Lautenschlager EP, Marshall GW, Marks KE, et al.: Mechanical strength of acrylic bone cements impregnated with antibiotics. J Biomed Mater Res 10:837-845, 1976 
Levin, PD: The effectiveness of various antibiotics in methylmethacrylate. J Bone Joint Surg 57B:234-237, 1975

Lindsay DS, Blagburn BL. Antiprotozoan drugs, in H.R. Adams (ed): Veterinary Pharmacology and Therapeutics (ed 7). Ames, Iowa, Iowa State University Press, 1995, pp 956-957

Lloyd KCK, Stover SM, Pascoe JR, et al.: Plasma and synovial fluid concentrations of gentamicin in horses after intra-articular concentrations of buffered and unbuffered gentamicin. Am J Vet Res 49:644-649, 1988

Marks KE, Nelson CL, Lautenschlager EP: Antibiotic-impregnated acrylic bone cement. J Bone Joint Surg 58:358-364, 1976

Martens RJ, Auer JA, Carter GK: Equine Pediatrics: Septic arthritis and osteomyelitis. $\underline{J}$ Am Vet Med Assoc 188:582-585, 1986

McIlwraith CW. Treatment of Infectious Arthritis. Vet Clinics North Am 5:363-379, 1983

Miclau T, Dahners LE, Lindsey RW: In vitro pharmacokinetics of antibiotic release from locally implantable materials. J Orthop Res 11:627-632, 1993

Moore RM: Pathogenesis of obligate anaerobic bacterial infections in horses. Comp Cont Educ 15:278-286, 1993a

Moore RM: Diagnosis and treatment of obligate anaerobic bacterial infections in horses. Comp Cont Educ 15:989-994, 1993b 
Moore RM, Schneider RK, Kowalski J, et al.: Antimicrobial susceptibility of bacterial isolates from 233 horses with musculoskeletal infection during 1979-1989. Equine Vet J 24:450-456, 1992

Nelson CL, Griffin FM, Harrison BH: In vitro elution characteristics of commercially and non-commercially prepared antibiotic PMMA beads. Orthop Rel Res 284:303-308, 1992

Osterberg B: Influence of capillary multifilament sutures on the antibacterial action of inflammatory cells in infected wounds. Acta Chir Scand 149:751-757, 1983

Penner MJ, Masri BA, Duncan CP: Elution characteristics of vancomycin and tobramycin combined in acrylic bone-cement. J Arthroplasty 11:939-944, 1996

Picknell B, Mizen L, Sutherland R, et al.: Antibacterial activity of antibiotics in acrylic bone cement. J bone Joint Surg 59-B:302-307, 1977

Plumb DC. Veterinary drug handbook (ed 2). White Bear Lake, MN, Pharma Vet Publishing, 1995, pp 320-323 and 451-454

Popham GJ, Mangino P, Seligson D, et al.: Antibiotic-Impregnated beads: Factors in antibiotic selection. Orthop Rev 20:331-337, 1991

Riviere JE, Spoo JW. Aminoglycoside antibiotics, in H. R. Adams (ed): Veterinary Pharmacology and Therapeutics (ed 7). Ames, Iowa, Iowa State University Press, 1995, pp 797-810

Salvati EA, Callaghan JJ, Brause BD, et al.: Reimplantation in infection. Elution of gentamicin from cement and beads. Clin Orthop 207:83-93, 1986

Santschi EM, Adams SB, Murphey ED. How to perform intravenous digital perfusion. In: Proc Amer Assoc Eq Pract 1998; 198-201 
Sayegh AI, Sande RD, Ragle CA, et al.: Appendicular Osteomyelitis in horses: Etiology, pathogenesis, and diagnosis. Compend Contin Educ 23: 760-766, 2001

Scher KS, Bernstein JM, Jones CW: Infectivity of vascular sutures. Am Surg 51:577-579, 1985

Schneider RK. Orthopedic Infections, in J. R. Auer and J. A. Stick (ed): Equine Surgery (ed 2). Philadelphia, PA, W. B. Saunders Company, 1999, pp 727-736

Schneider RK, Andrea R, Barnes HG: Use of antibiotic-impregnated polymethylmethacrylate for treatment of an open radial fracture in a horse. $\mathrm{J}$ Am Vet Med Assoc 207: 1454-1457, 1995

Schneider RK, Bramlage LR, Mecklenburg LM, et al.: Open drainage, intra-articular and systemic antibiotics in the treatment of septic arthritis / tenosynovitis in horses. Equine Vet J 24: 443-449, 1992

Schneider RK, Bramlage LR, Moore RM et al.: A retrospective study of 192 horses affected with septic arthritis/tenosynovitis. Equine Vet J 24:436-442, 1992.

Schurman DJ, Trindade C, Hirshman HP, et al.: Antibiotic-acrylic bone cement composites. J Bone Joint Surg 60-A:978-984, 1978

Snyder JR, Pascoe JR, Hirsh DC: Antimicrobial susceptibility of microorganisms isolated from equine orthopedic patients. Vet Surg 16:197-201, 1987

Specht TE, Brown MP, Gronwall RR et al. Pharmacokinetics of metronidazole and its concentrations in body fluids and endometrial tissues in mares. Am J Vet Res 53:18071812,1992 
Stead DA, Richards RME: Sensitive fluorimetric determination of gentamicin sulfate in biological matrices using solid-phase extraction, pre-column derivatization with 9fluorenylmethyl chloroformate and reversed-phase high-performance liquid chromatography. J Chromatogr B 675:295-302, 1996

Stead DA, Richards RME: Sensitive high-performance liquid chromatographic assay for aminoglycosides in biological matrices enables the direct estimation of bacterial drug uptake. J Chromatogr B 693:415-421, 1997

Sweeney RW, Sweeney CR, Soma LR, et al: Pharmacokinetics of metronidazole given to horses by intravenous and oral routes. Am J Vet Res 47: 1726-1729, 1986

Sweeney RW, Sweeney CR, Weiher J: Clinical use of metronidazole in horses: 200 cases (1984-1989). J Am Vet Med Assoc 198:1045-1048, 1991

Tobias KM, Schneider RK, Besser TE: Use of antimicrobial-impregnated polymethylmethacrylate. J Am Vet Med Assoc 208:841-845, 1996

Tripell SB: Current concepts review. Antibiotic-impregnated cement in total joint arthroplasty. J Bone Joint Surg 68-A:1297-1302, 1986

Trostle SS, Hendrickson DA, Stone WC et al: Use of antimicrobial-impregnated polymethylmethacrylate beads for treatment of chronic, refractory septic arthritis and osteomyelitis of the digit in a bull. J Am Vet Med Assoc 208:404-407, 1996

Venkateshwaran TG, Stewart JT: Determination of metronidazole in vaginal tissue by high performance liquid chromatography using solid-phase extraction. J Chromatogr B 672:300-304, 1995

Vidal J, Allieu Y: Utilisation de metacrylate de methyle pour combler les cavities d'osteite entendue des members. Rev. Chir. Orthop 55:158, 1969 
Wahlig H, Dingeldein E. Antibiotics and bone cements: Experimental and clinical longterm observations. Acta Orthop Scand 51: 49-56, 1980

Welch AB. Antibiotics in acrylic bone cement. In vitro studies. J Biomed Mat Res 12:679-700, 1978

Whitehair KJ, Adams SB, Parker JE, et al.: Regional limb perfusion with antibiotics in three horses. Vet Surg 21:286-292, 1992

Wilson KJ, Cierny G, Adams KR, et al.: Comparative evaluation of the diffusion of tobramycin and cefatoxime out of AIPMMA beads. J Orthop Res 6:279-286, 1988 


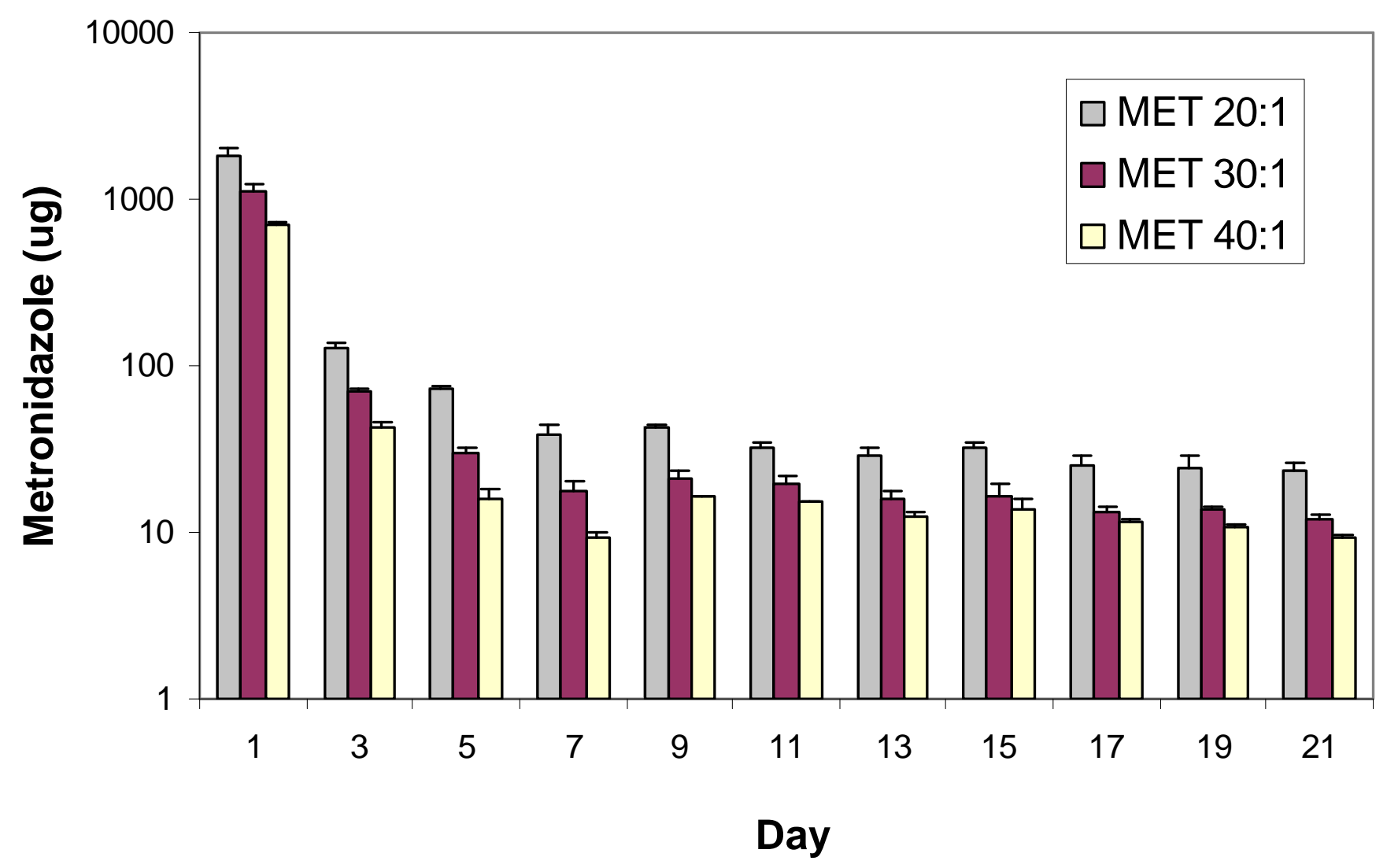

Figure 1 - Mean (+/- SEM) daily cumulative elution of metronidazole ( $\mu \mathrm{g})$ from triplicate incubations of ten $6 \mathrm{~mm}$ diameter PMMA beads containing metronidazole in 20:1 (MET 20:1), 30:1 (MET 30:1) or 40:1 (MET 40:1) ratios of PMMA to metronidazole. Data for even numbered days was not plotted. Elution from the MET 20:1 group was significantly greater than for MET 30:1 and MET 40:1 groups ( $\mathrm{p}<0.05$ ). Elution for the MET 30:1 group was significantly greater than for the MET 40:1 group for the first 7 days but not thereafter. 


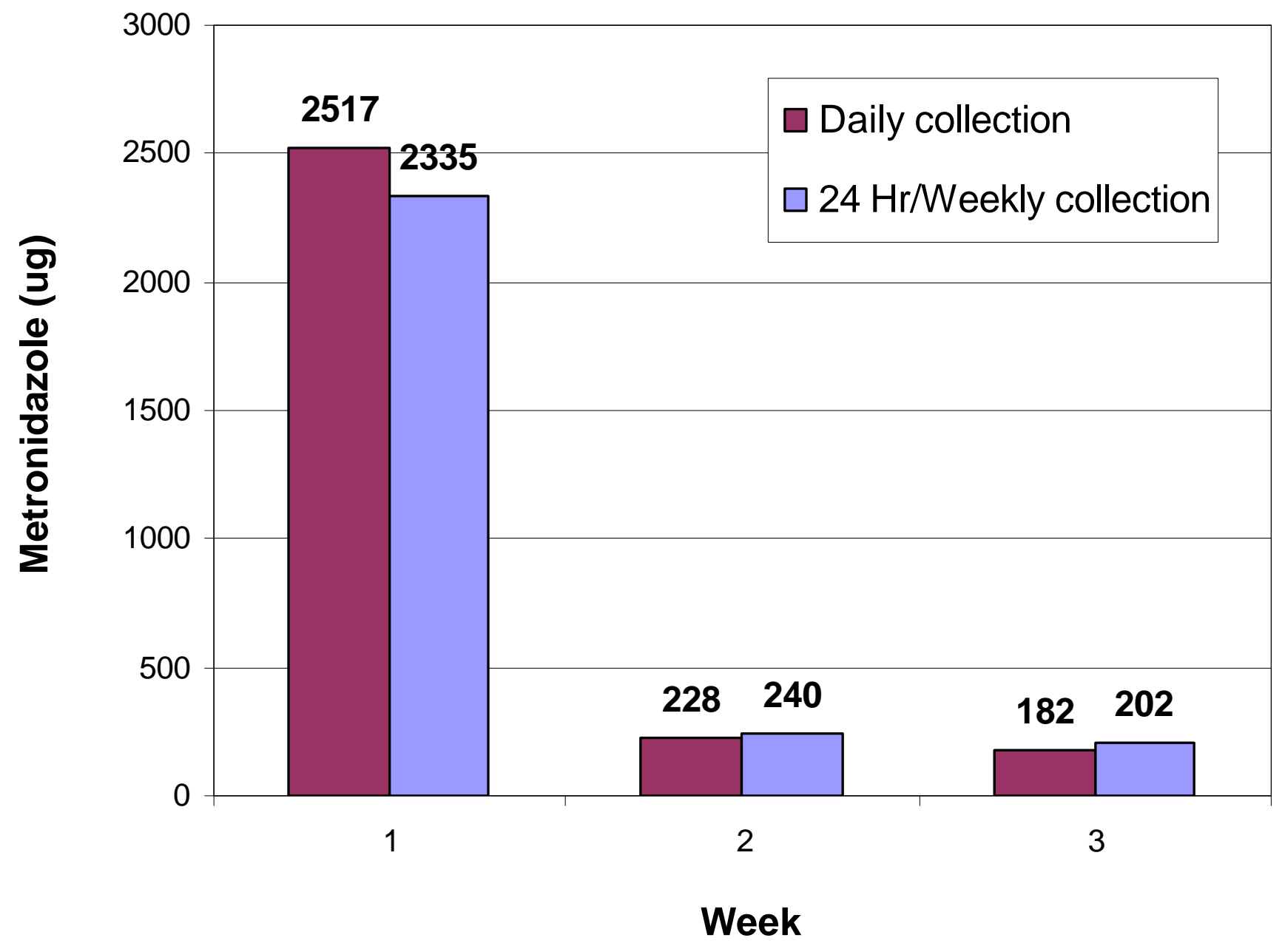

Figure 2- The effect of sampling interval on the elution of metronidazole from PMMA (MET 20:1) is depicted. Cumulative metronidazole elution in groups collected daily (saline changed 21 times) were similar to those collected 5 times during the first 24-hour period and then once a week for 3 weeks (saline changed 8 times). Data points represent the cumulative mean metronidazole concentration collected weekly for each of the three weeks. 


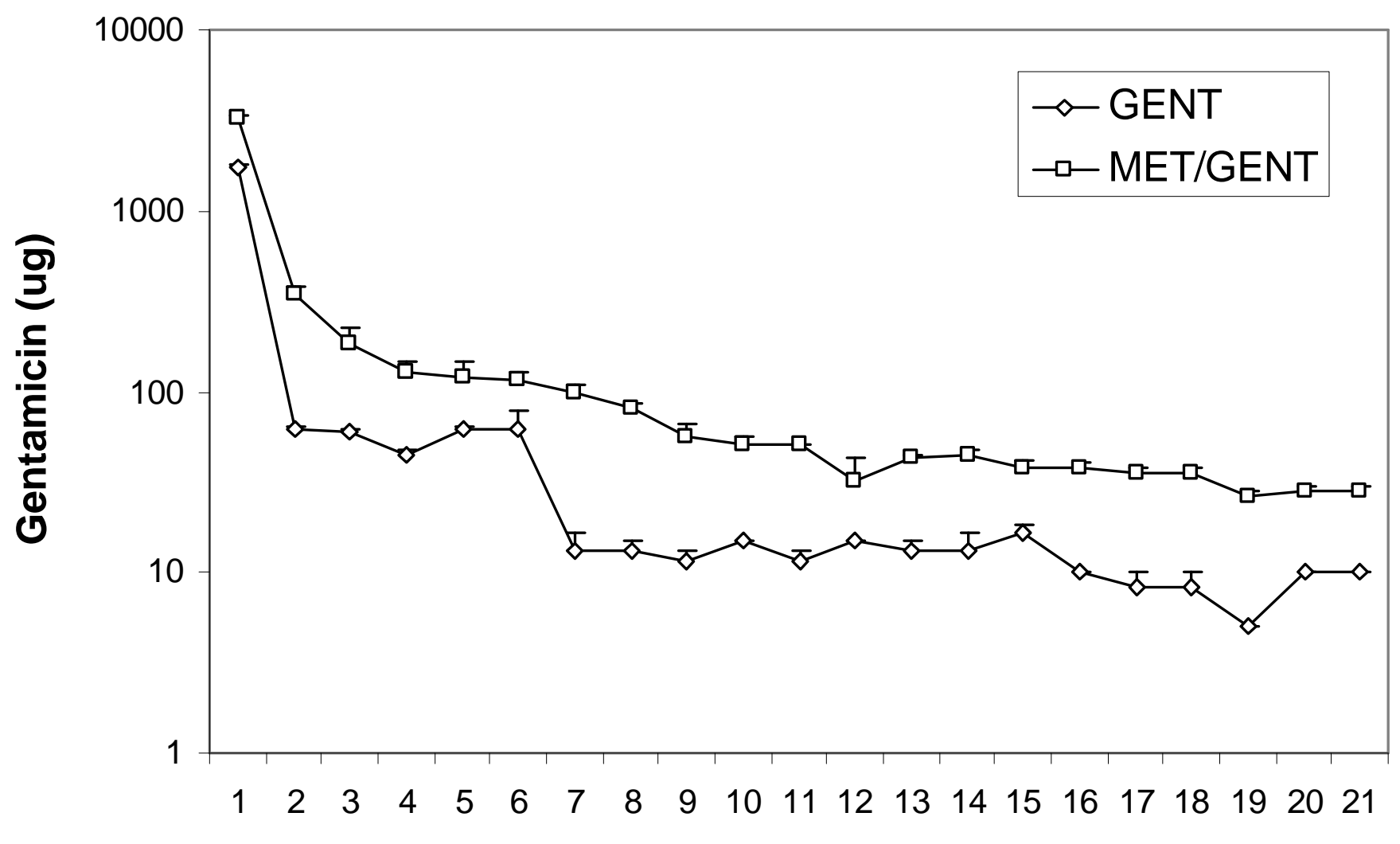

\section{Day}

Figure 3 - Mean (+/- SEM) daily cumulative elution of gentamicin $(\mu \mathrm{g})$ from triplicate incubations of ten $6 \mathrm{~mm}$ diameter PMMA beads containing gentamicin in 20:1 ratio (GENT) of PMMA to gentamicin and PMMA beads containing metronidazole and gentamicin in 20:1:1 ratio of PMMA, metronidazole and gentamicin (MET/GENT). Gentamicin elution was significantly greater for the MET/GENT throughout the 21-day period $(\mathrm{p}<0.05)$. 


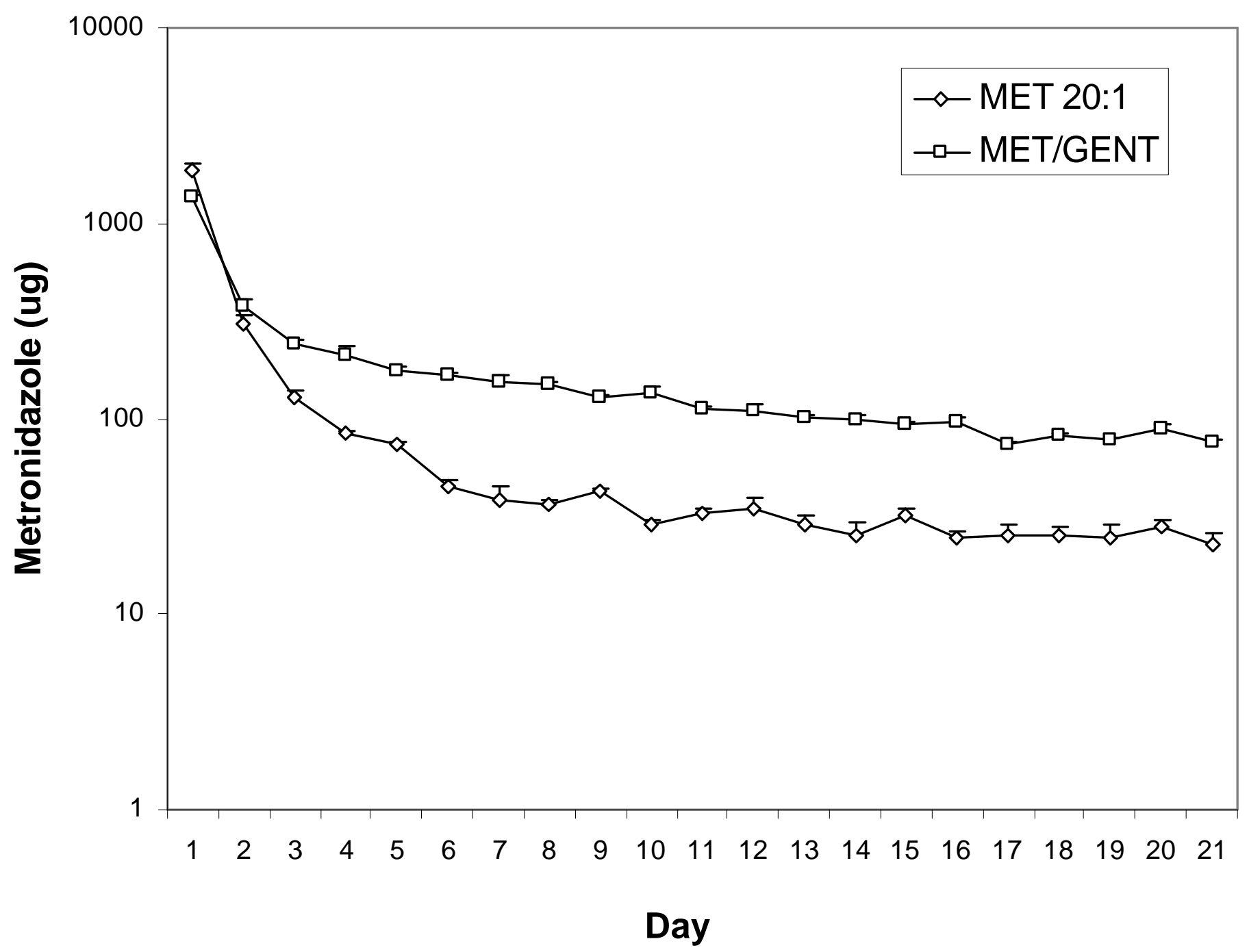

Figure 4 - Mean (+/- SEM) daily cumulative elution of metronidazole $(\mu \mathrm{g})$ from triplicate incubations of ten $6 \mathrm{~mm}$ diameter PMMA beads containing metronidazole in 20:1 ratio (MET 20:1) of PMMA to metronidazole and PMMA beads containing metronidazole and gentamicin in 20:1:1 ratio of PMMA, metronidazole and gentamicin (MET/GENT). Metronidazole elution was significantly greater for the MET/GENT group on days 3 through $21(\mathrm{p}<0.05)$. 


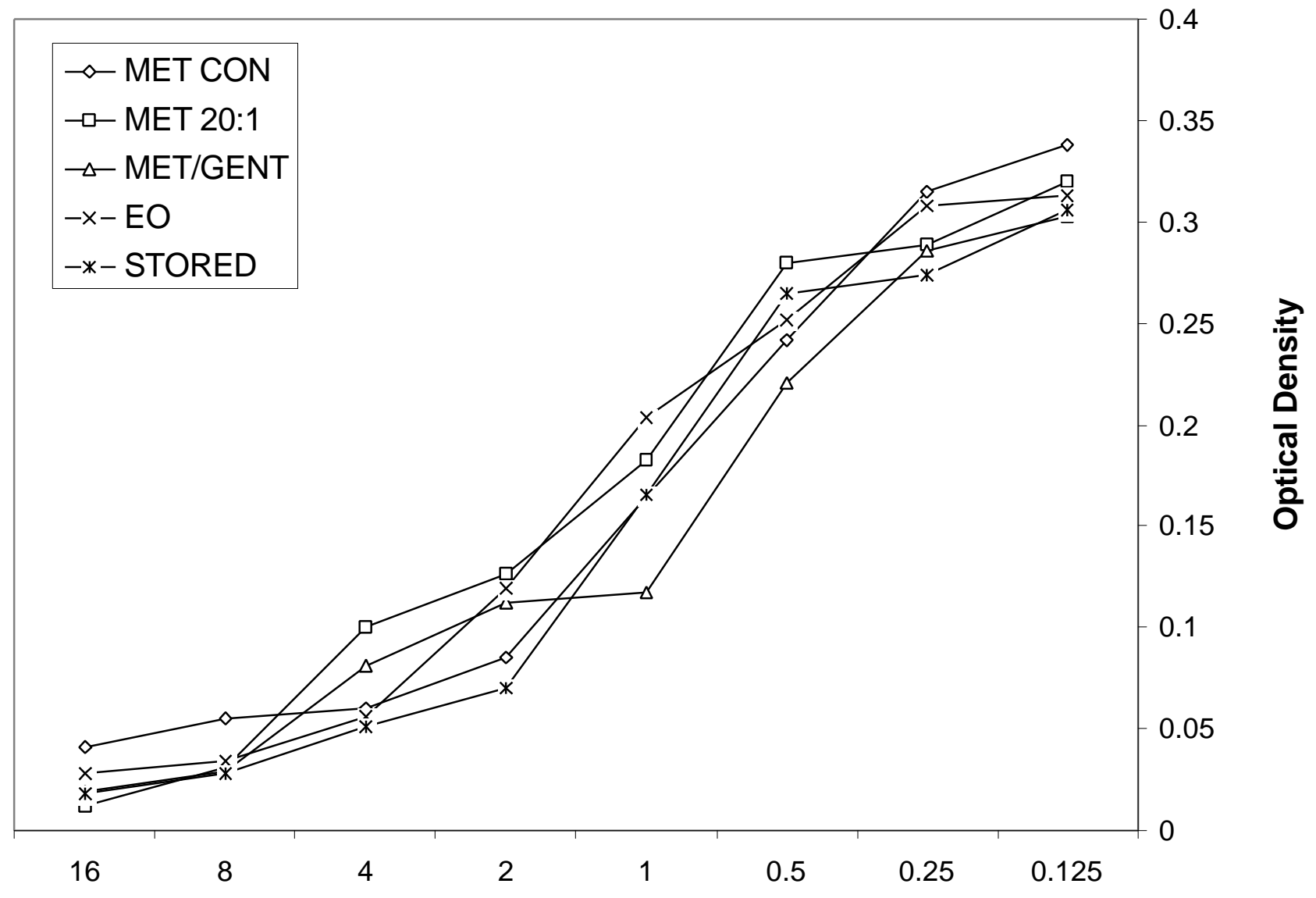

Metronidazole Concentration (ug/ml)

Figure 5 - The effect of serial dilutions of metronidazole on the $\mathrm{OD}_{620}$ of Bacteroides fragilis cultures at 48 hours of incubation. Groups evaluated were metronidazole control (MET CON), eluent from metronidazole-impregnated PMMA (MET 20:1), eluent from metronidazole and gentamicin-impregnated PMMA (MET/GENT), eluent from ethylene oxide sterilized metronidazole and gentamicin-impregnated PMMA (EO), and eluent from metronidazole and gentamicin-impregnated PMMA beads that had been sterilized using ethylene oxide and stored for 2 months at room temperature (STORED). Data points represent the mean optical density resulting from three experiments. Bacterial growth was not significantly different for any of the groups at any metronidazole concentration tested $(\mathrm{p}>0.05)$. 


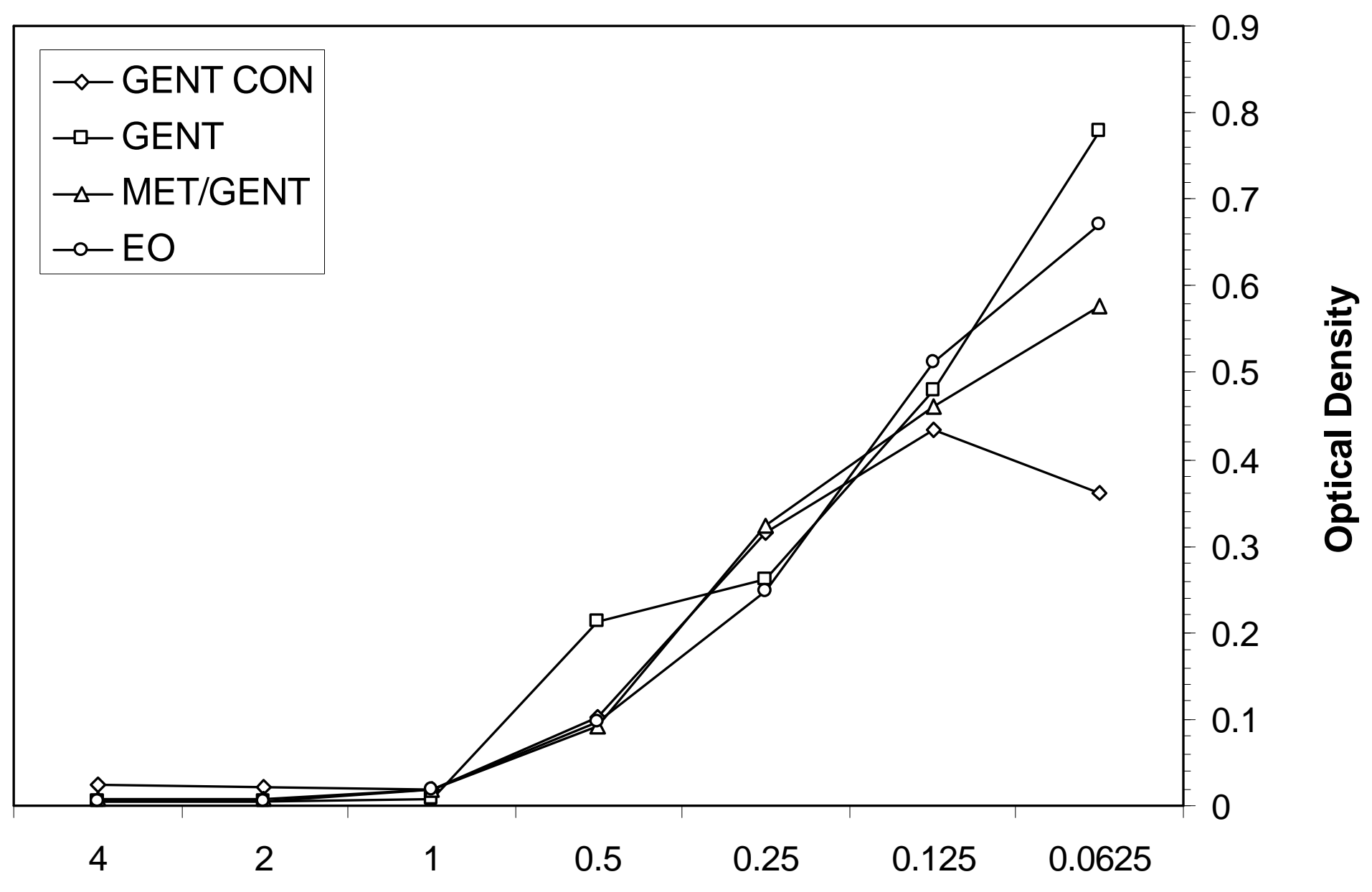

\section{Gentamicin Concentration ug/ml}

Figure 6 - The effect of serial dilutions of gentamicin on the $\mathrm{OD}_{620}$ Escherichia coli cultures at 24 hours of incubation. Groups evaluated were gentamicin control (GENT CON), eluent from gentamicin-impregnated PMMA (GENT), eluent from metronidazole and gentamicin-impregnated PMMA (MET/GENT), and eluent from ethylene oxide sterilized metronidazole and gentamicin-impregnated PMMA (EO). Data points represent the mean optical density resulting from three experiments. Bacterial growth was not significantly different for any of the groups at any gentamicin concentration tested $(\mathrm{p}>0.05)$. 


\section{VITA}

José Rafaelix Ramos was born in Santurce, Puerto Rico on June 7, 1971. He is the son of José Rafael (Rafo) Ramos of Barranquitas and Awilda Ortiz of Orocovis, Puerto Rico. He grew up in Barranquitas, a small town in central Puerto Rico. At 14 years of age, his parents moved to Ponce, a big city in the south of the island. He graduated from El Colegio Ponceño (high school) in May, 1989. After spending a year learning english at the University of Tampa, he moved to Texas A\&M University, from where he graduated in December 1993 with a Bachelor of Science Degree in Animal Science. In May 1998, he obtained his degree of Doctor of Veterinary Medicine from Tuskegee University in Tuskegee, Alabama. In July of that same year, he began a large animal medicine and surgery rotating internship at the Virginia-Maryland Regional College of Veterinary Medicine, Virginia Tech in Blacksburg, Virginia, which he successfully completed in June $30^{\text {th }} 1999$.

Since then he has been enrolled in the combined masters/clinical residency program in large animal surgery at this same institution. José presented the results of his

graduate work at the $14^{\text {th }}$ Annual Research Symposium, Virginia-Maryland Regional College of Veterinary Medicine in June 2002 and at the $12^{\text {th }}$ Annual Symposium of the American College of Veterinary Surgeons in October 2002. This work has also been published in Veterinary Surgery. Upon completion of the combined program, José, joined by his wife Flavia and his two daughters Flavia Alexandra and Isabella Andrea, will return to Puerto Rico with hopes of opening an equine hospital in his homeland. 